Goal Pursuits in Romantic Relationships: Does Attachment Moderate the Effect of Relationship Satisfaction?

by

Hannah Brazeau

A thesis submitted to the Faculty of Graduate and Postdoctoral Affairs in partial fulfillment of the requirements for the degree of

Master of Arts

in

Psychology

Carleton University

Ottawa, Ontario

C) 2017

Hannah Brazeau 


\begin{abstract}
The current research investigated how attachment orientation moderates the effect of relationship satisfaction on the pursuit of goals. Study one examined the extent to which attachment orientation moderated the effect of relationship satisfaction on the pursuit of short-term goals. Unfortunately, attachment orientation appeared not to be a significant moderator for this association, possibly due to the trivial nature of the identified short-term goals. Study two addressed this issue of goal triviality, as well as assessed whether increases and decreases in relationship satisfaction facilitated and inhibited goal pursuit, respectively. The results indicated that attachment anxiety was a significant moderator for this link as decreases in relationship satisfaction significantly reduced goal focus, perceived partner support, and goal motivation for those with low attachment anxiety. Overall, this research suggests that relationship satisfaction may be important to supporting the pursuit of long-term goals.
\end{abstract}

Keywords: attachment, goal pursuit, relationship satisfaction, romantic relationships 
Table of Contents

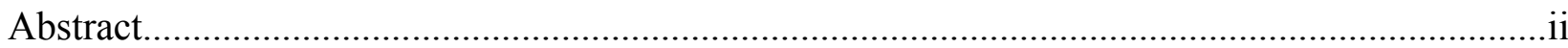

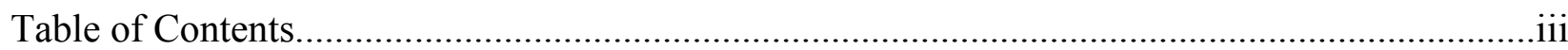

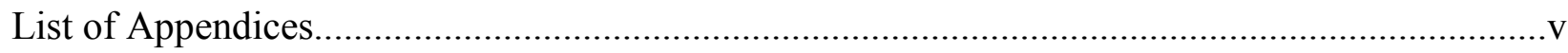

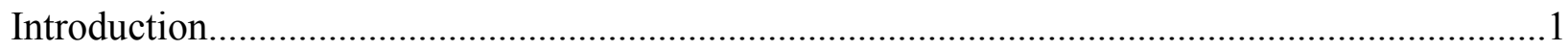

Attachment Theory Applied to Romantic Relationships............................................

Attachment Theory Applied to Goal Pursuits............................................................4

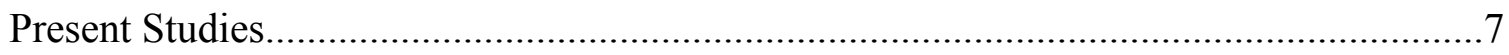

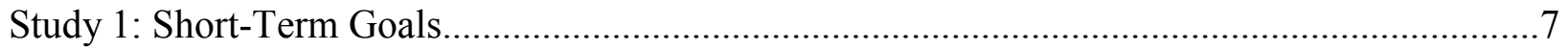

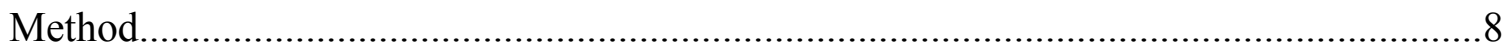

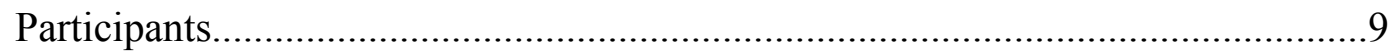

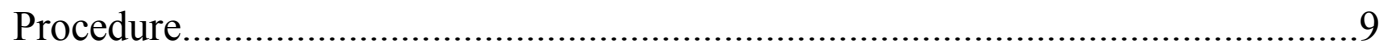

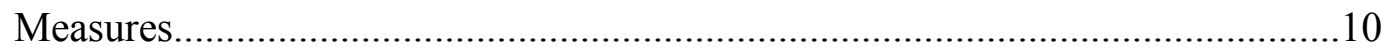

Attachment Orientation............................................................10

Goal Identification....................................................................11

Manipulation of Relationship Satisfaction......................................11

Pursuit of Goals............................................................................... 12

Relationship Satisfaction..............................................................13

Mood Restoration.................................................................. 13

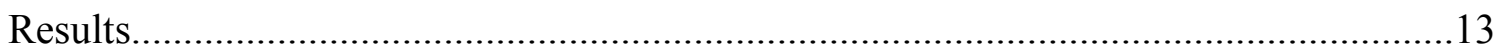

Preliminary Analyses.............................................................................. 13

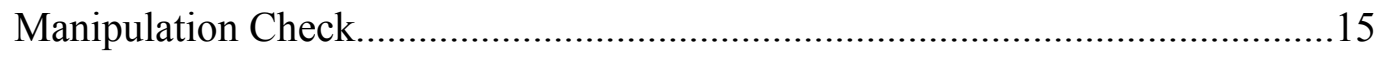

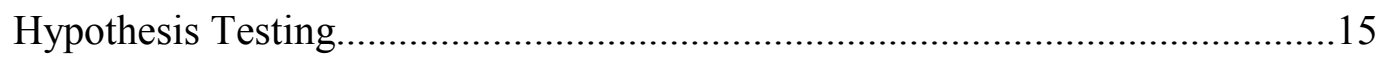

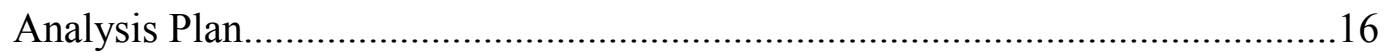

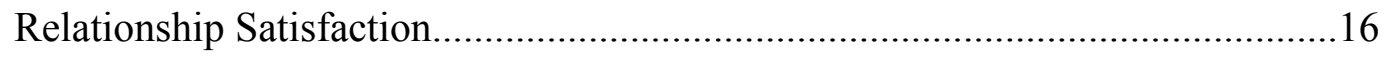




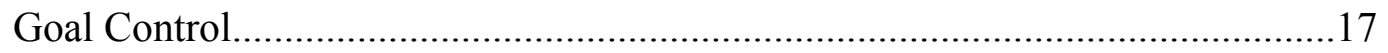

Goal Focus......................................................................................... 17

Perceived Partner Support....................................................................... 19

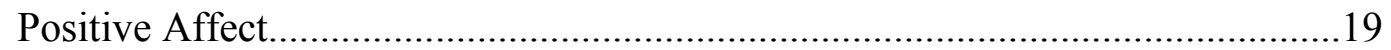

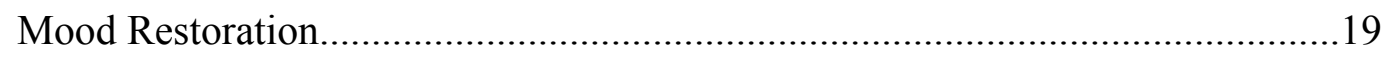

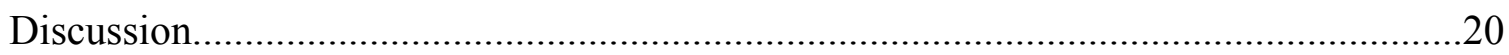

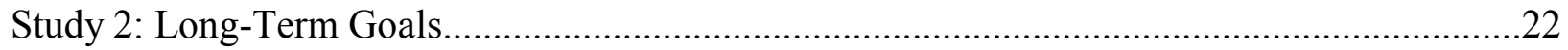

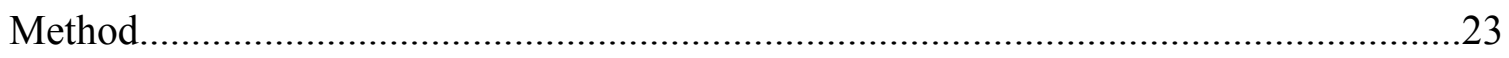

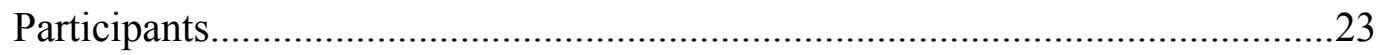

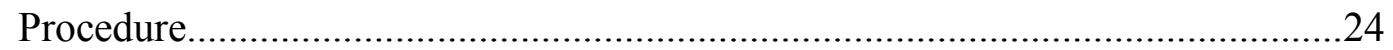

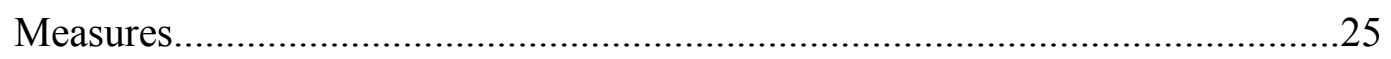

Attachment Orientation..............................................................25

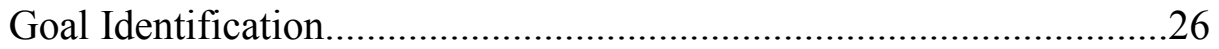

Manipulation of Relationship Satisfaction....................................26

Pursuit of Goals............................................................................22

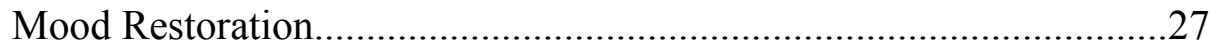

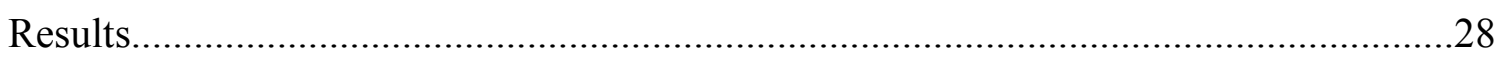

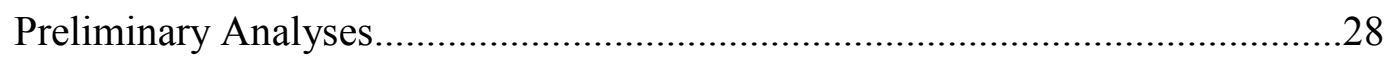

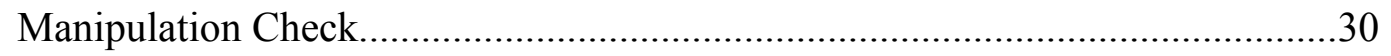

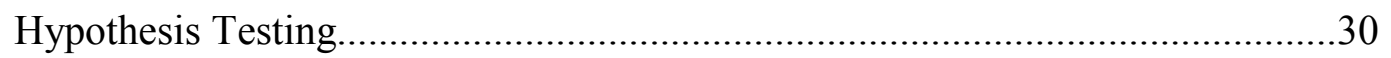

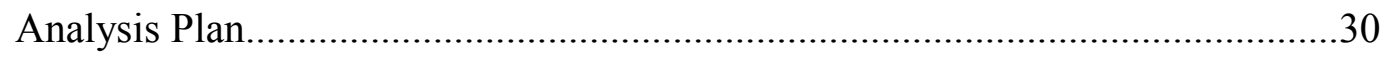

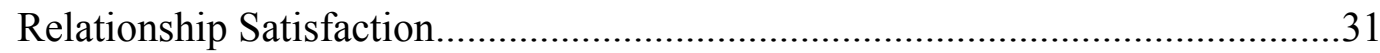

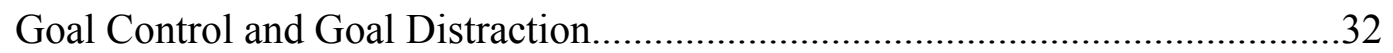

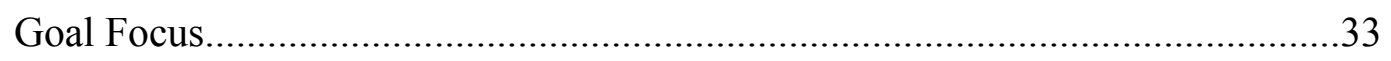

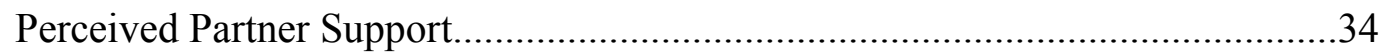




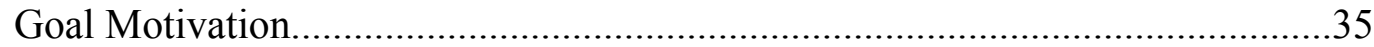

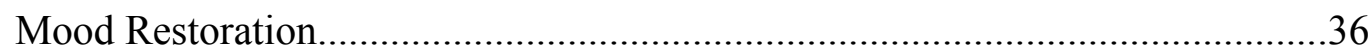

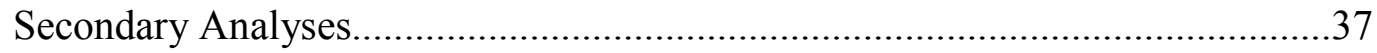

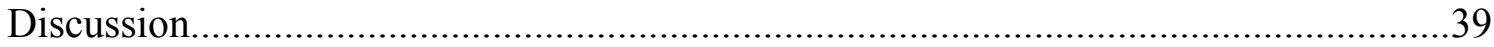

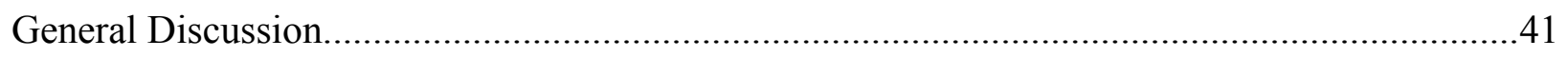

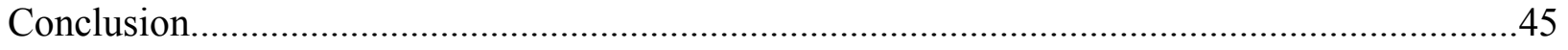

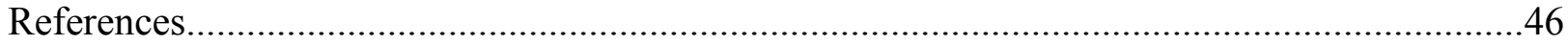

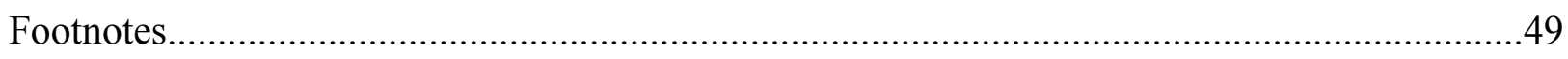

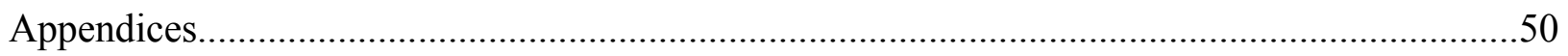




\section{List of Appendices}

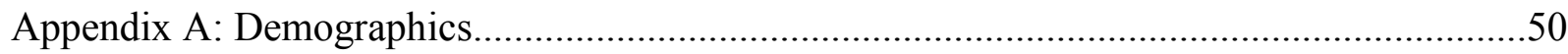

Appendix B: Experiences in Close Relationship Scale - Short Form..................................51

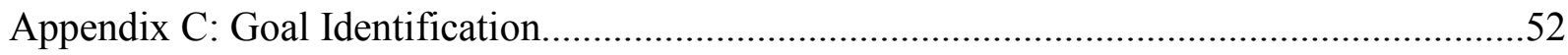

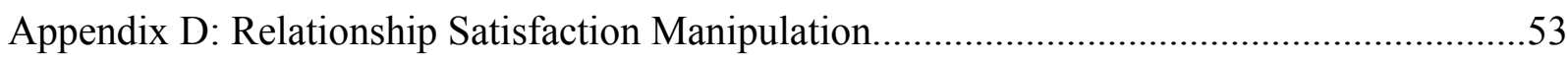

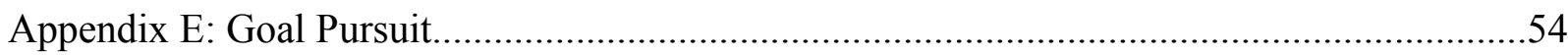

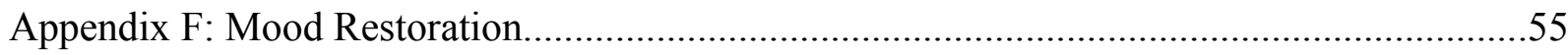

Appendix G: Results after Splitting by Sample Source ..................................................56

Appendix H: Results after Controlling for Goal Importance and Commitment......................62

Appendix I: Results for Participants with High Goal Importance.........................................65

Appendix J: Results after the Removal of the Control Group................................................68 
Goal pursuits in Romantic Relationships: Does Attachment Moderate the Effect of Relationship Satisfaction?

Romantic relationships are often central to a person's subjective well-being, and the status of a romantic relationship is often related to life satisfaction and happiness (Love \& Holder, 2015). If a romantic relationship is going well, life is grand, but if a relationship is dissatisfying, this dissatisfaction often spills over to other aspects of life. For instance, a recent study found that momentary fluctuations in relationship satisfaction affect a person's motivational mind-set, thereby altering perceived progress towards short-term goals (Hofmann, Finkel, \& Fitzsimons, 2015). Specifically, Hofmann et al. (2015) showed that when people feel greater relationship satisfaction, they feel that they are making greater progress towards short-term goals, but when people feel less relationship satisfaction, progress towards short-term goals suffers. These results suggest that when relationship stress is present personal pursuits become secondary to repairing the relationship.

Although the ups and downs of one's relationship may influence goal progress, the magnitude of this effect may depend on one's attachment orientation. According to attachment theory, attachment orientations are primarily active when a stressor is encountered, and once activated, the orientation motivates the individual to engage in specific behavioral and emotional strategies in order to cope with the stress (Bowlby, 1969; Simpson, Rholes, \& Nelligan, 1992). Thus, one's attachment orientation may influence how one responds to fluctuations in relationship satisfaction and the pursuit of goals. The current research aims to investigate how attachment orientation moderates the effect of relationship satisfaction on the pursuit of short and long-term goals.

\section{Attachment Theory Applied to Romantic Relationships}


The research on adulthood attachment is primarily based on a theory of infant attachment that was developed to describe and explain the bond that forms between an infant and a primary caregiver (Bowlby, 1969). Attachment theory was based on the observation that during times of stress infants go to extraordinary lengths (e.g., crying, clinging) to establish proximity to a primary caregiver. These behaviours are adaptive responses to stress that allow a child to gain access to an individual who provides the infant with support, protection, and care (i.e., an attachment figure). If an attachment figure is perceived to be nearby, accessible, and attentive, a child will feel secure and confident, which will allow him or her to explore environments, play with others, and be sociable. However, if an attachment figure is perceived to be distant, inaccessible, and disregarding, a child will likely experience an uneasiness that will motivate the infant to enact a range of attachment-seeking behaviors from searching for the primary caregiver to actively crying and clinging to the caregiver (Bowlby, 1969). During the development of attachment theory, Bowlby (1969) recognized that there were individual differences in the way that children evaluate the accessibility of an attachment figure and which attachment-seeking behaviors were enacted in response to stress. In order to explain these differences, Bowlby proposed that, based on the interactions that a child has with a primary caregiver, a child develops a specific attachment orientation that provides a guide for future relationship-related expectations, emotions, needs, and behaviours (Bowlby, 1969; Mikulincer \& Shaver, 2016).

The extension of infant attachment theory to adulthood attachment was based on the notion that the attachment processes responsible for the bond that develops between adults in romantic relationships are quite similar to the attachment processes responsible for the bond that develops between a caregiver and an infant (Fraley \& Shaver, 2000; Hazan \& Shaver, 1994). Therefore, much like in childhood, adults develop patterns of interpersonal cognitions, emotions, and behaviors (i.e., an attachment orientation) based on past experiences in interpersonal 
relationships (Bartholomew \& Horowitz, 1991; Fraley \& Shaver, 2000; Shaver \& Mikulincer, 2007). Specifically, within adulthood, there are two fundamental dimensions of attachment: (a) attachment anxiety, and (b) attachment avoidance (Brennan, Clark, \& Shaver, 1998; Fraley \& Shaver, 2000). The attachment anxiety dimension reflects an individual's tendency to worry and ruminate about close relationships because of an overall fear of rejection and abandonment, while the attachment avoidance dimension refers to an individual's tendency to experience discomfort in situations of emotional closeness or dependence. Due to the continuous nature of these two dimensions, people who score low on both dimensions are characterized as exhibiting attachment security, which refers to an individual's tendency to feel at ease with intimacy and autonomy (Brennan et al., 1998; Fraley \& Shaver, 2000; Hazan \& Shaver, 1994).

According to attachment theory, as well as more recent research, the attachment orientation of an individual is primarily active when a stressor is present. This activation motivates a person to engage in specific behaviours towards attachment figures as a way of coping with the stressor (Bowlby, 1969; Campbell, Simpson, Boldry, \& Kashy, 2005). Much like infant attachment, when no stressor is present, a person is free to explore personal interests and focus on personal goal pursuits (Fraley \& Shaver, 2000; Mikulincer \& Shaver, 2003; Shaver \& Mikulincer, 2002). However, when a stressor is present, people with different attachment orientations have been shown to interpret and respond to stress differently. Specifically, while experiencing conflict within a relationship or a relational threat, people who display a more anxious attachment orientation tend to engage in hyperactivating strategies, which involve seeking proximity to a romantic partner through behavioral and emotional actions, thus further activating the attachment system (for review, see Mikulincer \& Shaver, 2016). These strategies drive these individuals to be dependent upon others, relying on reassurances to regulate negative emotions. In particular, when faced with a relationship threat, more anxious individuals tend to become extremely 
attentive to the source of stress and obsess over the possibility of rejection or abandonment (Campbell \& Marshall, 2011; Campbell et al., 2005). In comparison, while experiencing conflict within a relationship or a relationship threat, people who display a more avoidant attachment orientation tend to enact deactivating strategies, which involve engaging in behavioral and emotional actions that distance one from a romantic partner, thereby deactivating the attachment system (for review, see Mikulincer \& Shaver, 2016). These strategies allow individuals who are more avoidant to maintain independence from a romantic partner, which is viewed as protective from attachment-related distress. For instance, research has indicated that when faced with a relationship threat these people tend to be more critical of a partner, tend not turn to a partner for support, and tend to ignore the emotional states of their relationship (Campbell et al., 2005; Simpson, Rholes, \& Neligan, 1992). Finally, while experiencing conflict within a relationship or a relationship threat, people who display a more secure attachment orientation tend to momentarily shift attention towards assessing the accessibility of one's romantic partner. However, these individuals have the general knowledge that one's romantic partner will be attentive and available in times of stress (i.e., a secure base), which allows for the deactivation of the attachment system (Shaver \& Mikulincer, 2016).

In sum, previous research has shown that attachment orientation is one important factor that influences how an individual interprets and copes with negative interpersonal situations, including relationship threats (Campbell \& Marshall, 2011; Campbell et al., 2005; Shaver \& Mikulincer, 2016; Simpson et al., 1992). However, an individual's attachment orientation may also influence how the person appraises and pursues goals.

\section{Attachment Theory Applied to Goal Pursuits}

There are many possible goals that an individual can choose to pursue and a number of ways that one can go about achieving those goals. Previous research suggests that in general 
people vary in terms of chosen goal pursuits, the degree of commitment to goal pursuits, the anticipated outcomes of goal pursuits, and the appraisal of threats that occur during goal pursuit (Emmons, 1997; Mikulincer \& Shaver, 2007). According to attachment researchers, because each attachment orientation uses a different set of strategies that have various regulatory processes, these differences can be explained by the individual's attachment orientation.

As previously discussed, hyperactivating strategies lead people who display more anxious attachment orientation to keep their attachment systems chronically activated, resulting in these individuals being alert to threats, slights, separations, and losses (Bowlby, 1969; Mikulincer \& Shaver, 2016). Chronic activation of the attachment system prevents these individuals from feeling safe enough to freely explore personal interests, thereby affecting which goals these people pursue, as well as appraisals of anticipated outcomes and threats that occur during goal pursuit (Bowlby, 1988; Grossmann, Grossmann, \& Zimmerman, 1999). Research suggests that, as a way to keep the attachment system activated, people who display a more anxious attachment orientation tend to hold pessimistic expectations about their abilities to achieve personal goals and often exaggerate the possibility of threat and failure during goalpursuit (Elliot \& Reis, 2003; Mikulincer \& Shaver, 2016). Thus, these individuals often present themselves as incapable and in need of frequent reassurances and support from an attachment figure (Mikulincer \& Shaver, 2016). Furthermore, research has indicated that relative to securely attached individuals, those who are anxiously attached tend to have a greater fear of failure due to the belief that the attachment figure will not be unconditionally responsive when threats or failures are encountered (Elliot \& Reis, 2003). When a threat is encountered during goal pursuit, the tendency to engage in hyperactivating strategies leads these individuals to exaggerate and prioritize the threat, thereby limiting the amount of effort, commitment, and focus that is placed towards personal goal pursuits (Elliot \& Reis, 2003). 
In contrast to the hyperactivating strategies of anxiously attached individuals, deactivating strategies lead people with a more avoidant attachment orientation to suppress the activation of the attachment system and inhibit proximity-seeking efforts (Bowlby, 1969; Mikulincer \& Shaver, 2016). The priority to suppress the attachment systems leads these individuals to neglect personal exploration, thus affecting the goals pursued, and the appraisals of anticipated outcomes and threats that occur during goal pursuit (Bowlby, 1988; Grossmann, Grossmann, \& Zimmerman, 1999). In an attempt to avoid the activation of the attachment system, people who display a more avoidant attachment orientation tend to avoid investing in demanding or challenging activities that may trigger pain and frustration (Mikulincer \& Shaver, 2003). This results in these individuals pursuing goals that are easily achievable and not representative of their abilities (Mikulincer \& Shaver, 2016). In support of this notion, research has found that people with greater attachment avoidance tend to report less commitment towards personal goal pursuits (Mikulincer \& Shaver, 2016), as well as a lower need for achievement (Elliot \& Reis, 2003). In general, the tendency to engage in deactivating strategies allows people who possess a more avoidant attachment orientation to ensure that the attachment system does not become activated when threats or failures are encountered during goal pursuits.

Finally, according to Bowlby (1969) increased security within an interpersonal relationship should lead to positive personal growth. Thus, those who display a more secure attachment orientation should feel free to explore personal interests and goals as these individuals feel secure within romantic relationships and are aware that one's partner will be available and attentive in times of difficulty (Elliot \& Reis, 2003; Mikulincer \& Shaver, 2016). This allows for individuals with a more secure attachment orientation to have a higher need for achievement and less fear of failure compared to those with an anxious or avoidant attachment orientation (Elliot \& Reis, 2003). This knowledge that an attachment figure will be available, 
supportive, and reassuring allows those who possess a more secure attachment orientation to freely pursue personal goal pursuits.

\section{The Present Studies}

The research reviewed indicates that attachment orientation differentially impacts goal pursuit (Bowlby, 1988; Elliot \& Reis, 2003; Mikulincer \& Shaver, 2016). Goal pursuit is also influenced by relationship satisfaction, as a recent study conducted by Hofmann et al.'s (2015) suggested that fluctuations in relationship satisfaction alter an individual's feelings towards shortterm goal pursuits. Namely, increases in relationship satisfaction have been shown to boost an individual's feelings of focus and control over goals, as well as perceived support by a romantic partner. However, to the best of my knowledge, no research has yet examined how the effect of relationship satisfaction on goal pursuit might be influenced by attachment orientation. Thus, the present research aimed to investigate whether attachment orientation moderates the effect of relationship satisfaction on the pursuit of goals.

\section{Study 1: Short-Term Goals}

The first study examined the extent to which attachment orientation moderated the effect of relationship satisfaction on the pursuit of short-term goals. Specifically, after identifying a current goal that could be completed within a day, and experiencing an experimental manipulation intended to increase or decrease relationship satisfaction, participants were asked to report levels of goal control, focus, perceived partner support, and positive affect felt toward the identified short-term goal. Based on attachment theory and the previous research linking it to goal pursuits, the following hypotheses were developed.

When attachment anxiety is high, an increase (relative to a decrease) in relationship satisfaction should result in higher levels of goal control, goal focus, perceived partner support, and positive affect toward a short-term goal. Theoretically, when there is no immediate threat to 
a romantic relationship, anxiously attached individuals should feel free to explore personal interests and focus on personal goal pursuits (Bowlby, 1969; Mikulincer \& Shaver, 2016). However, when relationship satisfaction is low, those with an anxious attachment will tend to respond to stress with hyperactivating strategies that should lead to a shift in focus away from personal nonattachment-related activities (i.e., the pursuit of goals) towards attachment-related activities, such as proximity seeking and restoring relationship security (Bowlby, 1969; Campbell \& Marshall, 2011; Campbell et al., 2005; Mikulincer \& Shaver, 2016). Thus, it was predicted that when attachment anxiety is high, a decrease in relationship satisfaction (relative to an increase) should result in lower levels of goal control, goal focus, perceived partner support, and positive affect toward short-term goals.

In contrast, previous research suggests that those who possess a more avoidant attachment orientation tend to minimize the importance of and commitment to goals in order to avoid activation of the attachment system (Elliot \& Reis, 2003). Thus, when attachment avoidance is high, an increase (relative to a decrease) in relationship satisfaction should result in lower levels of goal control, goal focus, perceived partner support, and positive affect toward a short-term goal. However, when the attachment system does become activated, these individuals respond to stress by enacting deactivated strategies that distance themselves from a romantic partner, thereby deactivating the attachment system (Bowlby, 1969; Mikulincer \& Shaver, 2016). So when attachment avoidance is high, a decrease in relationship satisfaction (relative to an increase) should result in higher levels of goal control, goal focus, perceived partner support, and positive affect toward short-term goals as an increased interest in personal short-term goals pursuits could function to establish physical and emotional distance from a romantic partner.

\section{Method}


Participants. For this study, 140 undergraduate students $\left(80 \%\right.$ female, $M_{\text {age }}=22.78, S D$ $=5.73$ ) were recruited from the subject pool in the psychology department of a large Canadian university, and 100 American adults $\left(63 \%\right.$ female, $\left.M_{a g e}=34.95, S D=11.72\right)$ were recruited from Amazon's Mechanical Turk. In compensation for their time, all undergraduate participants received a $0.25 \%$ grade-raising credit towards an undergraduate psychology course, while all participants recruited from Amazon's Mechanical Turk received $\$ 1.00$ compensation. In order to be eligible for participation in this study, participants had to indicate being currently involved in a romantic relationship. Due to this criterion, 29 participants from the undergraduate sample were excluded from this study after indicating a relationship status of 'single'. Another 18 participants were excluded from the sample for failing to complete the manipulation or manipulation checks. Thus, the final sample included a total of 193 participants $(71 \%$ female, $\left.M_{\text {age }}=22.78, S D=5.73\right), 93$ undergraduate students and 100 American adults from Amazon's Mechanical Turk. The average relationship length for the total sample was 72.12 months (SD $=96.60 ; M_{\text {student }}=35.84$ months and $M_{\text {mechanical turk }}=106.20$ month).

Procedure. To begin, all participants were first asked to read and agree to an informed consent before completing the online self-report survey. At the beginning of the survey, all participants were asked to identify their age and gender, as well as their relationship status, relationship length, and relationship commitment in order to determine eligibility. Next, each participant was asked to identify and explain a short-term goal that they intended to complete either that day or the following day. After a short-term goal had been identified, the Experiences in Close Relationships Scale - Short Form (ECR-SF; Wei, Russell, Mallinckrodt \& Vogel, 2007) was completed by all participants as an assessment of attachment orientation.

Following the completion of the ECR-SF, each participant was randomly assigned to read a scenario that was meant to either momentarily increase or decrease relationship satisfaction. 
After reading the assigned scenario, as a manipulation check, participants were asked to rate their current mood and current relationship satisfaction. Next, participants were asked to think back to the goal that they described at the beginning of the survey and indicate their level of goal control, level of goal focus, perceived partner support, and current level of positive affect. Following these questions regarding goal pursuit, participants were asked to complete the Relationship Satisfaction scale as a measure of overall relationship satisfaction (Rusbult, Martz \& Agnew, 1998).

Finally, as a mood restoration, participants who were assigned to experience a decrease in relationship satisfaction were asked to read over the positive scenario presented to those assigned to experience an increase in relationship satisfaction. Following the mood restoration, all participants were asked indicate their current mood. Once the survey was completed, all participants were given the opportunity to read over a written debriefing that outlined the purpose of the study. Overall, this online study followed the procedure outlined by Hofmann et al. (2015), with the addition of the ECR-SF (Wei et al., 2007) and the Relationship Satisfaction scale (Rusbult et al., 1998).

\section{Measures.}

Attachment orientation. The Experiences in Close Relationships Scale - Short Form (Wei et al., 2007) was used to assess the attachment orientation of participants. This 12-item selfreport measure contains two 6-item subscales, which assess each of the dimensions of attachment. The anxiety subscale measured the participants' tendencies towards anxious attachment, while the avoidance subscale measured the participants' tendencies towards avoidant attachment. These two subscales differentially correlate in expected ways with constructs related to anxiety (e.g., excessive reassurance seeking) and avoidance (e.g., fear of intimacy) (Wei et al., 2007). To complete this measure, participants were asked to rate how much they agree with each 
statement using a 7-point Likert scale, where $1=$ "strongly disagree" and 7 = "strongly agree". Within this study, the anxiety and avoidance subscales had reliabilities of $\alpha=0.77$ and $\alpha=0.79$, respectively. In comparison, Wei and colleagues (2007) reported reliabilities of $\alpha=0.78$ (anxiety) and $\alpha=0.84$ (avoidance). The correlation between attachment anxiety and attachment avoidance scores was $r(190)=.42, p=.01$, which is greater than that reported by Wei et al. $(2007 ; r=.19)$.

Goal identification. Participants were asked to think about and describe a goal that they intended to complete either that day or the following day. It was specified that it could be any nontrivial goal from any sphere of life, but it should not be the goal of completing the survey. The goal identification process occurred before the manipulation of relationship satisfaction in order to ensure that the manipulation did not affect which goal the individual identified as their current goal-pursuit. The most commonly reported goals were short-term work/academic goals (e.g., " present a presentation effectively for my peers", "finish an assignment for school"), domestic goals (e.g., "clean my apartment", "finish laundry and put it all away"), and health goals (e.g., "go to the gym after work today", "go to the gym tomorrow and eat healthy").

Manipulation of relationship satisfaction. Participants assigned to undergo a momentary increase in relationship satisfaction read the following positive scenario: "Imagine for a few minutes that you surprise your partner with reservations for a romantic weekend together. Take a minute to imagine where you would go (e.g., a cabin in Vermont), what you would like to do (e.g., ski, dine, hot-tub, and then curl up in front of fireplace), and the look on partner's face when you surprise them with the reservations". In contrast, participants assigned to undergo a momentary decrease in relationship satisfaction read the following negative scenario: "Imagine for a few minutes that you come home early from a trip away, planning to surprise your partner, and find them in bed with your best friend. You confront your 
partner who says they were going to tell you when you returned from your trip that they were planning to leave you for your best friend. Take a minute to imagine the look on their faces when you discover them in bed together, and how you would confront them." Prior research has demonstrated that similar manipulations have had significant momentary effects on relationship satisfaction (Hofmann et al, 2015).

To assess whether the two scenarios had the intended effect of raising or lowering relationship satisfaction, after reading the scenario, participants were asked to report their current feelings using a 5-point emotion slider, where $1=$ very unhappy (:) and $5=$ very happy (:) $)$, and current relationship satisfaction using a 7-point Likert scale, where $1=$ "not at all satisfied" and $7=$ "very satisfied".

Pursuit of goals. To measure pursuit towards the identified short-term goal, participants were asked to indicate their level of control ("How much do you feel in control over accomplishing this?"), level of focus (“How much do you think you will be able to focus on getting this done?" and "How much do you think you will be mentally distracted by other things when trying to get this done?"), perceived partner support ("How supportive or unsupportive do you feel your partner will be in your pursuit of this?" and "How much do you think your partner will make it easier or more difficult for you to accomplish this?"), and current level of positive affect ("How happy do you feel at the moment?"), each of which was rated on a 7-point Likert scale, where $0=$ "not at all" and $6=$ "very much". Following Hofmann et al. (2015), the twoitems measuring predicted level of focus, $r(191)=.39, p<.001$, and the two-items measuring perceived partner support, $r=.61, p<.001$, were combined to develop a measure of goal focus and a measure of support. These items and measures have been used in previous research to measure pursuit towards a goal (Hofmann et al., 2015). 
Relationship satisfaction. The Relationship Satisfaction scale (Rusbult et al., 1998) was used as a means to validate of the one-item measure of current relationship satisfaction. This five item self-report survey is a measure of relationship satisfaction and includes items such as: "My relationship with my partner is close to ideal". Participants were asked to indicate the degree to which they agreed with each of the statements using 9-point Likert scales, where $0=$ "do not agree at all", $4=$ "agree somewhat", and $8=$ "agree completely". This scale has been found to have strong correlations with constructs related to happiness in romantic relationships including commitment, relationship closeness, and dyadic satisfaction (Rusbult et al., 1998). For this study, this scale had excellent reliability with an $\alpha=0.97$. This is in line with Rusbult and colleagues (1998) who reported alphas ranging from 0.79 to 0.97.

Mood restoration. To ensure that no lasting negative effects were produced from the experimental manipulation, participants assigned to undergo a momentary decrease in relationship satisfaction were asked to read over the positive scenario presented to those assigned to undergo a momentary increase in relationship satisfaction. After reading over the scenario, participants were asked to report on their current feelings using a 5-point emotion slider $(1=$ very unhappy $(:)$ and $5=$ very happy $(()))$.

\section{Results}

Preliminary analyses. Since the participants for this study came from two sources (i.e., participant pool from a Canadian university and Mechanical Turk), a series of independent sample $t$-tests was conducted to compare the student sample and the Mechanical Turk sample on key variables. The results of these analyses are detailed in Table 1. Briefly, the Mechanical Turk sample was significantly older than the student sample, and involved in significantly longer romantic relationships. Further, the Mechanical Turk sample reported significantly less attachment anxiety, and significantly more goal focus when compared to the student sample. 
These two samples did not differ significantly on any of the other key variables included in the study. For the analyses that follow, the two samples were combined. However, sample source was controlled for when analyzing goal focus as the two samples significantly differed from one another on this variable.

The correlations between the attachment orientations, the manipulation, and the goal factor (i.e., goal control, goal focus, goal distraction, perceived partner support, and positive affect) are presented in Table 2 . The results indicated that attachment anxiety and attachment avoidance were significantly related to all goal factors.

Table 1

Means, Standard Deviations, and Test Statistics for all Measures

\begin{tabular}{|c|c|c|c|c|c|c|}
\hline & & Total & $\underline{\text { Student }}$ & Mechanical Turk & & \\
\hline Measures & Min.-Max. & $M$ & $M(\mathrm{SD})$ & $M(\mathrm{SD})$ & $\mathrm{t}$ & $p$ \\
\hline Age (Yr.) & $18-84$ & 29.05 & $22.78(5.73)$ & $34.95(11.72)$ & -9.10 & $<.001$ \\
\hline \multicolumn{7}{|l|}{ Relationship Factors } \\
\hline $\begin{array}{l}\text { Relationship Length } \\
\text { (Mos.) }\end{array}$ & $2-646$ & 72.11 & $35.84(57.71)$ & $106.20(112.00)$ & -5.45 & $<.001$ \\
\hline Commitment & $1-7$ & 6.53 & $6.49(0.73)$ & $6.57(0.94)$ & -0.67 & .506 \\
\hline Relationship Satisfaction & $0-8$ & 6.34 & $6.39(1.90)$ & $6.31(1.93)$ & 0.28 & .779 \\
\hline Attachment Anxiety & $1-7$ & 3.36 & $3.66(1.14)$ & $3.08(1.25)$ & 3.36 & .001 \\
\hline Attachment Avoidance & $1-7$ & 2.29 & $2.35(0.94)$ & $2.24(1.04)$ & 0.71 & .481 \\
\hline \multicolumn{7}{|l|}{ Goal Pursuit Measures } \\
\hline Goal Control & $1-7$ & 5.90 & $5.78(1.37)$ & $6.02(1.31)$ & -1.27 & .207 \\
\hline Goal Focus & $1-7$ & 4.51 & $4.16(1.37)$ & $4.83(1.36)$ & -3.36 & .001 \\
\hline Perceived Partner Support & $1-7$ & 5.55 & $5.73(1.25)$ & $5.39(1.46)$ & 1.78 & .076 \\
\hline Current Happiness & $1-7$ & 5.29 & $5.40(1.40)$ & $5.18(1.58)$ & 1.04 & .298 \\
\hline
\end{tabular}


Table 2.

Correlations between the attachment orientations, the manipulation, and goal factors.

\begin{tabular}{|c|c|c|c|c|c|c|c|}
\hline & 1. & 2. & 3. & 4. & 5. & 7. & 8. \\
\hline 1. Attachment Anxiety & - & & & & & & \\
\hline 2. Attachment Avoidance & $.42 * *$ & - & & & & & \\
\hline 3. Manipulation & $.16^{*}$ & -.03 & - & & & & \\
\hline 4. Goal Control & $-.22 * *$ & $-.16^{*}$ & -.02 & - & & & \\
\hline 5. Goal Focus & $-.41 * *$ & $-.23 * *$ & .00 & $.55 * *$ & - & & \\
\hline 6. Partner Support & -.11 & $-.29 * *$ & $.19 * *$ & $.36^{* *}$ & $.25 * *$ & - & \\
\hline 7. Positive Affect & $-.26 * *$ & $-.30 * *$ & $.22 * *$ & $.33 * *$ & $.34 * *$ & $.60 * *$ & - \\
\hline
\end{tabular}

Manipulation check. In order to ensure the experimental manipulation led to changes in relationship satisfaction, an independent samples $t$-test compared the current mood and current relationship satisfaction of participants assigned to read the negative and positive scenarios. The results revealed that participants assigned to read the positive scenario reported significantly better moods $(M=4.64, S D=.70)$ than participants assigned to read the negative scenario $(M=$ $1.38, S D=.72), t(190)=-31.99, p<.001$, as well as significantly higher relationship satisfaction on the single item measure $(M=6.07, S D=1.14)$ than participants assigned to read the negative scenario $(M=5.05, S D=1.94), t(192)=-4.47, p<.001$. This indicates that the experimental manipulation of relationship satisfaction was successful. The manipulation also had an effect on the five-item relationship satisfaction scale, such that those imagining the positive scenario scored higher on the relationship satisfaction scale $(M=6.67, S D=1.65)$ than those who imagined the negative scenario $(\mathrm{M}=6.05, \mathrm{SD}=2.09), t(191)=-2.30, p=.022$. The single-item relationship satisfaction measure correlated with the multi-item scale, $r(191)=.69, p<.001$. It should be noted that participants across the conditions did not differ by age, $t(192)=1.14, p=$ .256 , relationship length, $t(192)=1.01, p=.315$, or relationship commitment, $t(189)=-1.54, p=$ .126 .

\section{Hypothesis testing.}


Analysis plan. To test whether the link between relationship satisfaction and goal pursuit differed as a function of attachment orientation, a series of moderated regression analyses was conducted. Prior to the regressions, the two attachment subscales (i.e., attachment avoidance and attachment anxiety) were centered, the manipulation variable was contrast coded (negative scenario $=-1$, positive scenario $=1$ ), and the multiplicative interactions of each attachment subscale with the contrast coded manipulation variable were computed. In all analyses, both anxious attachment scores (centered) and avoidant attachment scores (centered) were entered so that the effect of anxious attachment on any given variable controls for the effect of avoidant attachment and vice versa. Significant interactions were plotted (using points 1SD above and below the anxious and avoidant attachment means) to aid interpretation (Preacher, Curran \& Bauer, 2006).

Relationship satisfaction. To assess the extent to which attachment orientation moderated the effect of the relationship satisfaction manipulation, the single-item assessment of current relationship satisfaction (i.e., the manipulation check) was regressed on anxious attachment, avoidant attachment, the contrast coded manipulation, as well as the interaction terms. Consistent with the manipulation check results, reading the positive scenario resulted in higher current relationship satisfaction, $b=.58, S E=.11, t=5.40, p<.001$. Whereas avoidant attachment was associated with lower relationship satisfaction overall, $b=-.30, S E=.12, t=$ $2.57, p=.011$, it did not moderate the effect of the manipulation, $b=-.12, S E=.12, t(186)=-$ $1.037, p=.301$. Anxious attachment also predicted lower relationship satisfaction overall, $b=-$ $.35, S E=.10, t(186)=-3.61, p<.001$, and, unlike the case of avoidant attachment, also interacted with the manipulation, $b=.20, S E=.10, t=2.10, p=.037$. The negative scenario reduced current relationship satisfaction for participants with high attachment anxiety to a larger extent, $b=.82, S E=.16, t=5.23, p<.001$, than for those with low attachment anxiety, although 
the negative scenario did lead to lower satisfaction for participants with low attachment anxiety, $b=.33, S E=.16, t=2.05, p=.04$. These results are presented in Figure 1 .

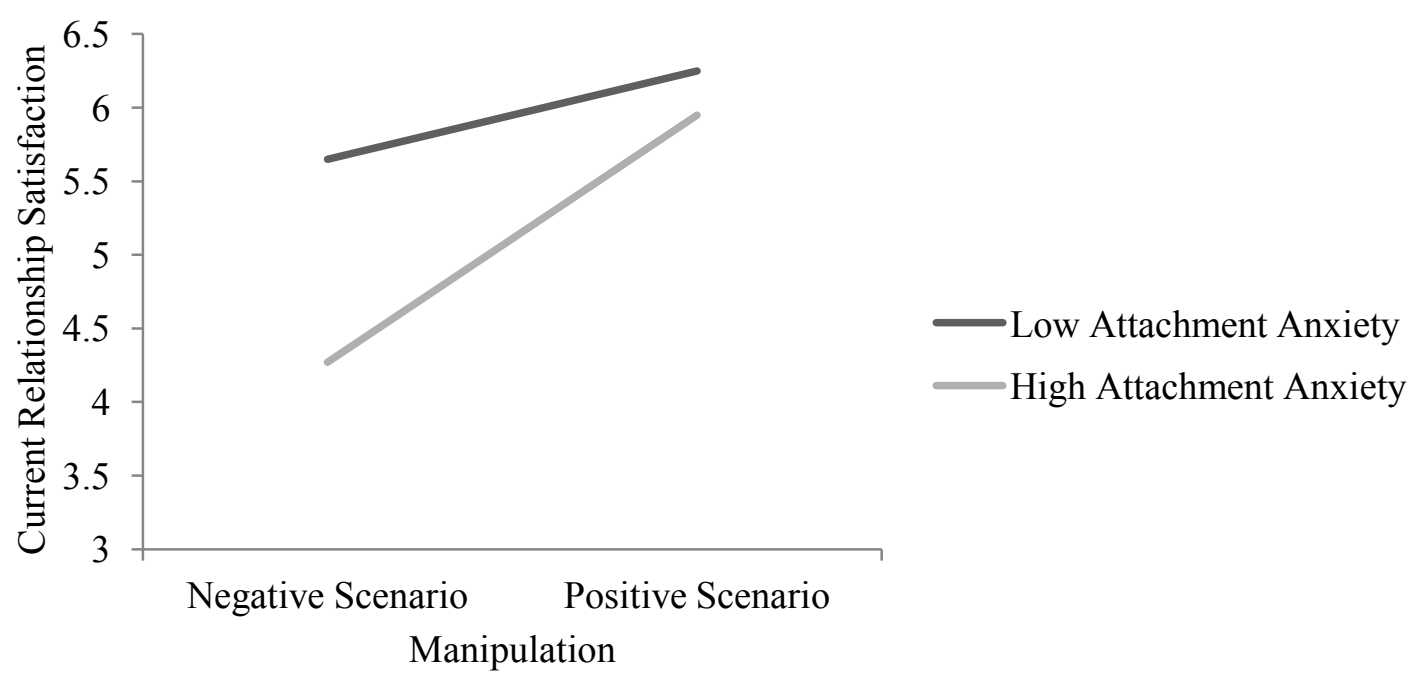

Figure 1. Graphical representation of the interaction of anxiety scores by the manipulation on current relationship satisfaction.

Goal control. Regression analyses predicting goal control did not yield a significant main effect of the relationship satisfaction manipulation $(p=.98)$. Moreover, the hypothesized interactions of attachment orientations with the relationship satisfaction manipulation were not significant $(p \mathrm{~s}>.40)$, however there was a significant main effect of attachment anxiety indicated that those with greater attachment anxiety tended to report lower goal control $(b=-.19$, $p=.027)$. These results are provided in Table 3 .

Goal focus. In the regression analyses predicting goal focus, there was no main effect of the relationship satisfaction manipulation $(p>.40)$. However, the hypothesized avoidant attachment by relationship satisfaction manipulation interaction was significant $(b=-.21, p=$ .046). Simple effects analyses indicated that for participants with low attachment avoidance the positive relationship scenario significantly increased goal focus, $b=.28, S E=.13, t=2.09, p=$ .038 , whereas no effect of the manipulation was evident for participants with high attachment 
avoidance, $b=-.11, S E=.13, t=-.86, p=.394$. These results are presented in Figure 2. Although the anxious attachment by relationship satisfaction interaction was not significant $(p>.70)$, a significant main effect of attachment anxiety $(b=-.40, p<.001)$ was observed, such that greater anxiety was associated with less goal focus. Details of the regression analyses are outlined in Table 3. Note that sample source was included in these analyses since the samples differed significantly on goal focus.

Table 3.

Regression of Attachment and Manipulation on Goal Control and Goal Focus in Study 1.

Predictor Variable

Goal Control

\begin{tabular}{lll}
\multicolumn{4}{c}{ Goal Focus } \\
\hline$b$ & se & $t$
\end{tabular}

Relationship Satisfaction Manipulation

$\begin{array}{llll}.00 & .10 & 0.02 & .98\end{array}$

$\begin{array}{llll}-.19 & .09 & -2.22 & .027\end{array}$

Attachment Anxiety

$\begin{array}{llll}-.13 & .11 & -1.18 & .24\end{array}$

.08

10

0.83

Attachment Avoidance

$\begin{array}{llll}.00 & .09 & 0.03 & .97\end{array}$

$-.40$

$.09-4.54<.001$

Anxiety x Relationship Satisfaction

$\begin{array}{llll}-.09 & .11 & -0.80 & .43\end{array}$

$-.14$

11

$-1.28$

21

Avoidance $x$ Relationship Satisfaction

$-.09$

.03

.09

0.32

.21

$-.21 \quad .11$

$-2.00 \quad .046$

Sample (MTurk)

$\begin{array}{llll}.47 & .19 & 2.43 & .016\end{array}$

Note: For relationship satisfaction manipulation, $-1=$ negative relationship scenario; $+1=$ positive relationship scenario. For Sample, $1=$ MTurk and $0=$ student sample. $N=189$.

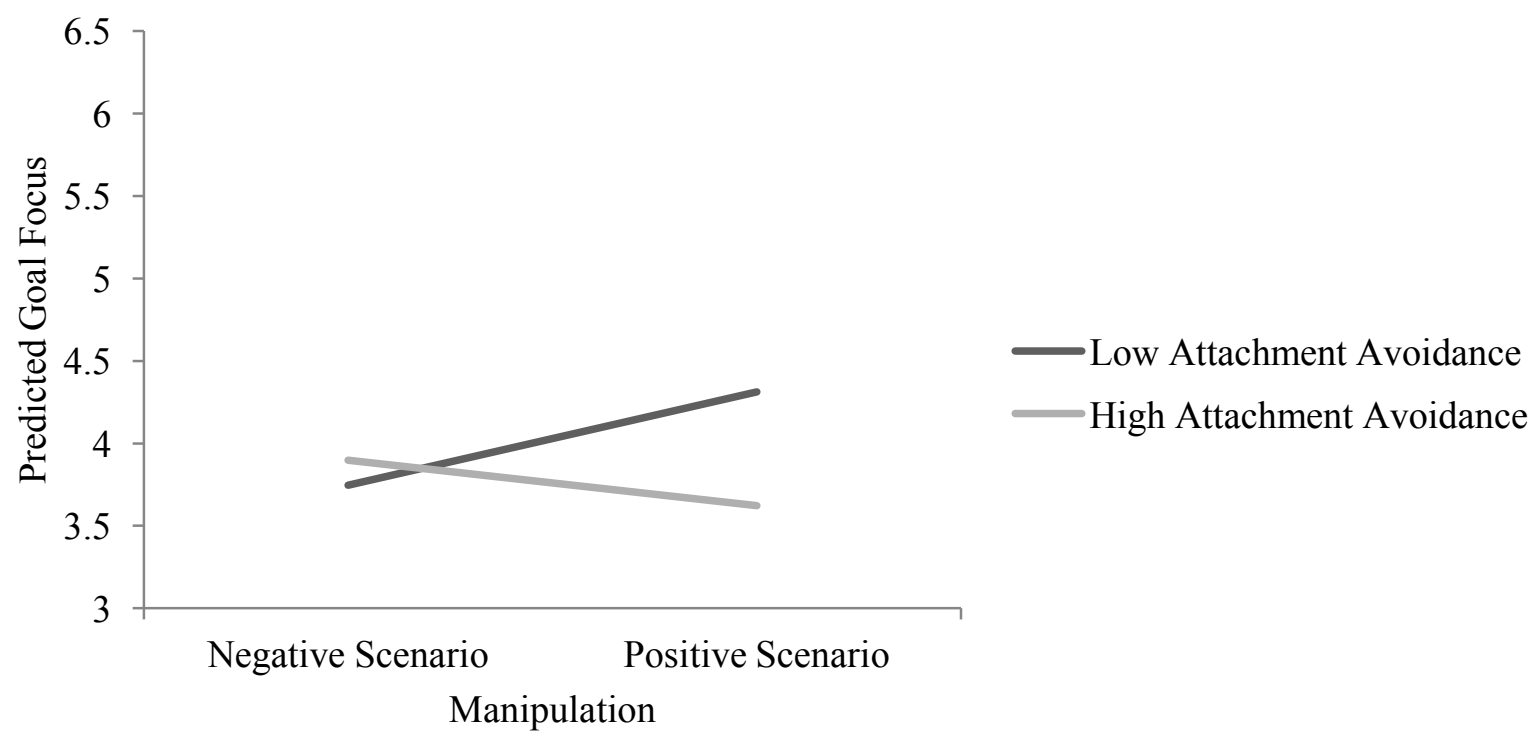

Figure 2. Graphical representation of the interaction of avoidance scores by the manipulation on predicted goal focus. 
Perceived partner support. The relationship satisfaction boost significantly increased perceived partner support $(b=.26, p=.007)$, but the hypothesized interactions of relationship satisfaction by attachment orientations were not significant $(p s>.40)$. However, a main effect of attachment avoidance $(b=-.37, p=.001)$ was observed, such that those with greater attachment avoidance tended to perceive lower partner support. The details of these analyses are provided in Table 4.

Positive affect. Similar to results for perceived partner support, the relationship satisfaction manipulation significantly increased positive affect $(b=.37, p<.001)$. As with the analyses for partner support, the hypothesized interactions of relationship satisfaction by attachment orientations were not significant $(p s>.40)$. Although the attachment orientation interactions were not significant, main effects were observed such that higher scores on both attachment anxiety and attachment avoidance were associated with lower positive affect. The results of these analyses are provided in Table 4.

Table 4

Regression of Attachment and Manipulation on Partner Support and Affect in Study 1.

\begin{tabular}{|c|c|c|c|c|c|c|c|c|}
\hline \multirow[b]{2}{*}{ Predictor Variable } & \multicolumn{4}{|c|}{ Perceived Partner Support } & \multicolumn{4}{|c|}{ Positive Affect } \\
\hline & $b$ & se & $t$ & $p$ & $b$ & se & $t$ & $p$ \\
\hline Relationship Satisfaction Manipulation & .26 & .10 & 2.74 & .007 & .37 & .10 & 2.72 & $<.001$ \\
\hline Attachment Anxiety & -.03 & .09 & -.34 & .73 & -.27 & .09 & -2.96 & .003 \\
\hline Attachment Avoidance &.- .37 & .11 & -3.51 & .001 & -.29 & .11 & -2.58 & .011 \\
\hline Anxiety x Relationship Satisfaction & .06 & .09 & .63 & .53 & -.04 & .09 & -.45 & .65 \\
\hline Avoidance $\mathrm{x}$ Relationship Satisfaction & -.09 & .10 & -.85 & .40 & .09 & .11 & .77 & .45 \\
\hline
\end{tabular}

Mood restoration. To ensure that reading the positive scenario did restore the mood of participants assigned to undergo the momentary decrease in relationship satisfaction, an independent samples $t$-test was conducted comparing the current mood (collected at the end of the study) of participants assigned to read the negative and positive scenarios. The results revealed that after the mood restoration, participants assigned to read the positive scenario $(M=$ 
$4.43, S D=.86$ ) were no longer significantly happier than participants assigned to read the negative scenario $(M=4.62, S D=.61), t(187)=1.82, p=.071$. This indicates that the mood restoration was successful.

\section{Discussion}

This study examined the extent to which attachment orientation moderated the effect of relationship satisfaction on the pursuit of short-term goals. Although imagining the scenarios differentially affected individuals with attachment anxiety (i.e., individuals with high attachment anxiety were more reactive, reporting much lower current relationship satisfaction after reading the negative scenario), attachment orientation did not appear to be a significant moderator for the effect of relationship satisfaction on goal control, perceived support, and positive affect for shortterm goals. However, avoidant attachment was found to be a significant moderator for the effect of relationship satisfaction on goal focus, as people with lower attachment avoidance reported significantly higher goal focus after reading the positive scenario. This result suggests that improving the status of a romantic relationship may facilitate an individual's focus on short-term goal pursuits.

Although attachment orientations did not seem to moderate the effect of relationship satisfaction on most goal-related factors, main effects of attachment orientation on a number of the goal-related factors were found. Specifically, people with higher levels of attachment anxiety tended to report lower goal control, goal focus, and positive affect, while those with higher attachment avoidance tended to report lower perceived partner support and positive affect. The results for anxious attachment are consistent with previous research suggesting that people who possess a more anxious attachment orientation tend to engage in hyperactivating strategies, which prioritize seeking comfort from a partner, resulting in these individuals shifting focus away from nonattachment related activities, such as short-term goal pursuits (Elliot \& Reis, 
2003; Mikulincer \& Shaver, 2016). Likewise, the results for avoidant attachment are consistent with previous research indicating that people who display a more avoidant attachment orientation tend to enact deactivating strategies, which prioritize self-reliance through distancing oneself from one's partner, leading them to hold more negative and critical views of others (Campbell et al., 2005; Mikulincer \& Shaver, 2016; Simpson et al., 1992).

Although the experimental manipulation was found to be effective in altering the relationship satisfaction of the participants, the results of this study were not consistent with Hofmann et al.'s (2015) study. Notably, although reading the manipulation did affect relationship satisfaction as intended, it did not have a significant effect on goal control or goal focus. The manipulation of relationship satisfaction did, however, affect perceived partner support and positive affect such that those participants imagining the positive scenario perceived greater partner support and positive affect than did those imagining their partner's infidelity. This supports the intuitive notion that a relational threat, such as the one posed in this study, would lead an individual to experience an array of negative feelings, and perhaps be less inclined to rely on his or her partner for support.

It is concerning that the relationship satisfaction manipulation did not have an effect on goal control or goal focus, as was found in Hofmann et al. (2015). Upon inspection of the reported short-term goals, many of the chosen goals were fairly inconsequential (e.g., "go for a walk with my son", "get to work", "I need to get the lawn mowed"). These goals may still have been easy to achieve even when a relationship threat was present. This limitation may account for the failure to support the hypotheses and previous research. Further, although the results suggest that improving relationship satisfaction may facilitate an individual's focus on goal pursuits, this cannot be determined unambiguously as there was not a no-manipulation control group included in the study. Study 2 attempted to address these limitations. 


\section{Study 2: Long -Term Goals}

The purpose of Study 2 was to extend Study 1 in two ways. First, to address the issue of goal triviality, participants in this study were asked to bring to mind and describe a longer-term goal, one that presumably would require more concentration and effort to be accomplished. Second, a control condition was added to the manipulation of relationship satisfaction in an effort to assess whether increasing relationship satisfaction facilitated goal pursuit and whether decreasing relationship satisfaction inhibited goal pursuit. As Hofmann et al. (2015) did not include a no-manipulation control group (as was followed in Study 1), it was ambiguous whether the effect of the manipulation on goal control, focus, and partner support was a facilitation effect or an inhibition effect. Overall, this study followed the same procedure as Study 1, with the exception of asking participants to identify a goal that would be completed over the next few months.

Based on these similarities, the hypotheses and rationales for Study 2 were consistent with those presented in Study 1. Briefly, when attachment anxiety is high, a decrease in relationship satisfaction (relative to an increase) should result in lower levels of goal control, goal focus, perceived partner support, and goal motivation toward long-term goals. In contrast, previous research suggests that those who possess a more avoidant attachment orientation tend to minimize the importance of and commitment to goals in order to avoid activation of the attachment system (Elliot \& Reis, 2003). Thus, when attachment avoidance is high, an increase (relative to a decrease) in relationship satisfaction should result in lower levels of goal control, goal focus, perceived partner support, and goal motivation toward long-term goals. However, for these individuals a decrease in relationship satisfaction (relative to an increase) should result in higher levels of goal control, goal focus, perceived partner support, and goal motivation toward 
long-term goals as a way of establishing physical and emotional distance from a romantic partner.

The addition of a control group led to the development of a set of hypotheses concerning whether the manipulation would facilitate or inhibit goal pursuit. Previous research suggests that when no stressor or threat is present a person should be able to continue pursuing ongoing activities and feel free to explore personal interests and goal pursuits (Fraley \& Shaver, 2000; Mikulincer \& Shaver, 2003; Shaver \& Mikulincer, 2002). However, Bowlby (1969) recognized that increased security within an interpersonal relationship should lead to positive personal growth. Thus, experiencing an increase in relationship satisfaction may: a) allow an individual to maintain a steady level of pursuit towards one's goals or, b) lead to the facilitation of one's goal pursuits. In contrast, when a stressor or threat is present focus should be momentary shifted towards assessing the availability of one's partner (Mikulincer \& Shaver, 2016). Hence, a decrease in relationship satisfaction should inhibit one's goal pursuits.

\section{Method}

Participants. Before any participants were recruited for this study, an a priori statistical power analysis was performed to determine a sufficient sample size for this study. Based on the significant avoidant attachment by manipulation interaction for goal focus found in Study 1 ( $b=$ $-.21, S E=.11, t=-2.00, p=.046)$, the estimated effect size for this study was 0.018 . This is considered to be a medium effect size using Aguinis, Beaty, Boik, and Pierce (2005) criteria for moderation analyses. With an alpha $=.05$ and power $=0.80$, the projected sample size needed with this effect size (GPower) is approximately $N=527$. Thus, for this study, 320 undergraduate students $\left(81 \%\right.$ female, $\left.M_{\text {age }}=20.53, S D=5.51\right)$ were recruited from the subject pool in the psychology department of a large Canadian university, and 488 American adults (58\% female, $\left.M_{\text {age }}=34.99, S D=10.65\right)$ were recruited from Amazon's Mechanical Turk. Following data 
collection, all undergraduate participants received a $0.25 \%$ grade-raising credit toward an undergraduate psychology course, while all participants recruited from Amazon's Mechanical Turk received $\$ 1.00$ as compensation for their time. In order to be eligible for participation in this study, participants had to indicate being currently involved in a romantic relationship. Due to this criterion, 38 participants from the undergraduate sample and 38 participants from the Mechanical Turk sample were excluded from this study after selecting 'single' as their relationship status or indicating having no commitment to their current romantic partner. Another 37 participants from the undergraduate sample and 20 participants from the Mechanical Turk sample were excluded from the sample for failing to complete the manipulation or manipulation checks. Finally, 14 participants from the undergraduate sample and 7 participants from the Mechanical Turk sample were excluded from the sample for failing to identify a long-term goal. Thus, the final sample included a total of 654 participants, 231 undergraduate students $(85 \%$ female, $\left.M_{\text {age }}=21.03, S D=6.16\right)$ and 423 American adults $\left(61 \%\right.$ female, $M_{\text {age }}=35.28, S D=$ 10.66) from Amazon's Mechanical Turk. The average relationship length for the total sample was 75.32 months $\left(S D=85.31 ; M_{\text {undergraduate }}=34.29\right.$ months and $M_{\text {mechanical turk }}=97.73$ months $)$.

Procedure. To begin, all participants were given the opportunity to read and agree to an informed consent before completing an online self-report survey. At the beginning of the survey, all participants were asked to indicate their age and gender, as well as their relationship status, relationship length, and commitment level to determine eligibility. Next, participants were asked to identify and explain a long-term goal that they intended to complete over the next few months. Following the identification of a long-term goal, each participant was asked to indicate how important that goal was to them, how difficult that goal would be to achieve, and how committed they were to achieving that goal. Next, participants completed the Experiences in Close 
Relationships Scale - Short Form (ECR-SF; Wei et al., 2007) as an assessment of attachment orientation.

Once the ECR-SF had been completed, each participant was randomly assigned to one of three experimental conditions. Similar to Study 1, approximately two-thirds of the sample ( $n=$ 435) read a scenario that was meant to either momentarily increase or decrease relationship satisfaction. However, unique to Study 2, one-third $(n=219)$ of the sample did not read a scenario, and instead completed the survey without experiencing an experimental manipulation. As a manipulation check, those who experienced the experimental manipulation were asked to report on their current mood, and all participants, including those in the control condition, were asked to indicate their current relationship satisfaction. Next, participants were asked to think back to the long-term goal that was described at the beginning of the survey and indicate their level of goal control, goal focus, and perceived partner support. In addition, participants were asked to indicate how motivated they were to accomplish the identified goal, and how much effort they were willing to invest into accomplishing that goal.

Finally, as a mood restoration, participants assigned to read the negative scenario, meant to decrease relationship satisfaction, were asked to read over the positive scenario, meant to increase relationship satisfaction. Next, all participants were asked to indicate their current mood. Once the survey was completed, participants were given the opportunity to read over a written debriefing that outlined the purpose of the study. Overall, this online study followed the procedure outlined by Hofmann et al. (2015), with the addition of a control group, as well as the ECR-SF (Wei et al., 2007).

\section{Measures.}

Attachment orientation. Following the procedure of Study 1, the Experiences in Close Relationships Scale - Short Form (Wei et al., 2007) was used to assess the attachment orientation 
of participants. The details of this measure are outlined in Study 1. Within this study, the anxiety and avoidance subscales had reliabilities of $\alpha=0.76$ and $\alpha=0.83$, respectively. In comparison, Wei and colleagues (2007) reported reliabilities of $\alpha=0.78$ (anxiety) and $\alpha=0.84$ (avoidance). The correlation between attachment anxiety and attachment avoidance scores was $r(652)=.31, p$ $<.001$, which was similar to that found in Study $1, r(190)=.42, p=.01$, and greater than that reported by Wei et al. $(2007 ; r=.19)$

Goal identification. Participants were asked to think about and explain a long-term goal that they intended to complete over the next few months. It was specified that it could be any significant goal from any sphere of life. As in Study 1, the goal identification process occurred before the manipulation of relationship satisfaction in order to ensure that the manipulation did not affect which goals the participants identified as a current goal-pursuit. The most commonly reported goals were work/academic goals (e.g., "get a promotion at work", "I would like to increase my GPA from a 9 to a 10"), and health goals (e.g., "I want to lose 20 pounds", "I intend to quit smoking"). Unique to Study 2, participants were also asked to indicate the goal importance ("How important is this goal to you?"), goal difficulty ("How difficult is this goal for you to achieve"?), and goal commitment ("How committed are you to achieving this goal?") on a 7-point Likert scale, where $0=$ "not at all" and $6=$ "very much".

Manipulation of relationship satisfaction. The scenarios presented to each condition were the same as those presented in Study 1. The results of Study 1 indicated that this manipulation had significant momentary effects on relationship satisfaction. Unique to Study 2, a portion of the sample was assigned to a no-manipulation control group that completed the survey without experiencing the experimental manipulation. To assess whether the two scenarios had the intended effect of raising or lowering relationship satisfaction, participants who experienced an experimental manipulation were asked to report on their current feelings using a 5-point 
emotion slider, where $1=$ very unhappy $(:)$ and $5=$ very happy $(\odot)$. Following the manipulation all participants, including those who were assigned to the control group, were asked to indicate their current relationship satisfaction using a 7-point Likert scale, where $1=$ "not at all satisfied" and 7 = "very satisfied".

Pursuit of goals. To measure pursuit towards long-term goals, participants were asked think back to the goal that was identified at the beginning of the study and indicate their level of control ("How much do you feel in control over accomplishing this?"), focus ("How much do you think you will be able to focus on getting this done?" and "How much do you think you will be mentally distracted by other things when trying to get this done?"), and perceived partner support ("How supportive or unsupportive do you feel your partner will be in your pursuit of this?" and "How much do you think your partner will make it easier or more difficult for you to accomplish this?"). Each of these questions were answered using a 7-point Likert scale, where 0 $=$ "not at all" and $6=$ "very much". Following Hofmann et al. (2015), the two-items measuring perceived partner support, $r(655)=.66, p<.001$, were combined to develop a measure of goal support. Unlike Study 1, the two-items measuring goal focus were not combined due to the low correlation between the items, $r(654)=.29, p<.001$.

Unique to this study, participants were asked to indicate their goal motivation ("How motivated are you to accomplish this?" and "How much effort are you willing to invest in realizing this goal?). These two items were combined to develop a measure of goal motivation, $r(655)=.76, p<.001$. The above items and measures have been used in previous research to measure pursuit towards a goal (Hofmann et al., 2015).

Mood restoration. To ensure that no lasting negative effects were produced from the experimental manipulation, participants assigned to undergo a momentary decrease in relationship satisfaction were asked to read over the positive scenario presented to those assigned 
to undergo a momentary increase in relationship satisfaction. After reading over the scenario, participants were asked to report on their current feelings using a 5-point emotion slider $(1=$ very unhappy $(:)$ and $5=$ very happy $((;))$ ). The results of Study 1 indicated that reading the positive scenario successfully restored the mood of those assigned to undergo a momentary decrease in relationship satisfaction.

\section{Results}

Preliminary analyses. Since the participants for this study came from two sources (i.e., participant pool from a Canadian university and Amazon's Mechanical Turk), a series of independent sample $t$-tests was conducted to compare the student sample and the Mechanical Turk sample on the key variables of this study. The results of these analyses are detailed in Table 5. Briefly, similar to Study 1, the Mechanical Turk sample was significantly older than the student sample, and involved in significantly longer romantic relationships. The Mechanical Turk sample reported significantly more attachment avoidance, as well as more goal difficulty and goal commitment when compared to the student sample. Further, the Mechanical Turk sample reported significantly more goal control, as well as significantly less goal distraction and perceived partner support when compared to the student sample. These two samples did not differ significantly on any of the other key variables included in this study.

The correlations between the attachment orientations, the manipulation, and the goal factor (i.e., goal control, goal focus, goal distraction, perceived partner support, and goal motivation) are presented in Table 6 . The results indicated the attachment anxiety and attachment avoidance were significantly related to all goal factors. 
Table 5

Means, Standard Deviations, and Test Statistics for all Measures

\begin{tabular}{|c|c|c|c|c|c|c|}
\hline Measures & Min.-Max. & $\frac{\text { Total }}{M}$ & $\frac{\text { Student }}{M(\mathrm{SD})}$ & $\frac{\text { Mechanical Turk }}{M(\mathrm{SD})}$ & $\mathrm{t}$ & $p$ \\
\hline Age (Yr.) & $17-75$ & 30.26 & $21.03(6.16)$ & $35.28(10.66)$ & $\begin{array}{l}- \\
18.64\end{array}$ & $<.001$ \\
\hline \multicolumn{7}{|l|}{ Relationship Factors } \\
\hline $\begin{array}{l}\text { Relationship Length } \\
\text { (Mos.) }\end{array}$ & $4-516$ & 75.32 & $34.29(47.63)$ & $97.73(92.74)$ & -9.72 & $<.001$ \\
\hline Commitment & $1-7$ & 6.68 & $6.67(0.70)$ & $6.69(0.73)$ & -0.40 & .687 \\
\hline Attachment Anxiety & $1-7$ & 3.50 & $3.59(1.07)$ & $3.45(1.29)$ & 1.39 & .166 \\
\hline Attachment Avoidance & $1-7$ & 2.14 & $2.00(0.90)$ & $2.22(1.02)$ & -2.66 & .008 \\
\hline \multicolumn{7}{|l|}{ Goal Pursuit Measures } \\
\hline Goal Importance & $1-7$ & 6.50 & $6.46(0.76)$ & $6.52(0.75)$ & -0.99 & .322 \\
\hline Goal Difficulty & $1-7$ & 5.19 & $4.86(1.34)$ & $5.37(1.30)$ & -4.75 & $<.001$ \\
\hline Goal Commitment & $1-7$ & 6.28 & $6.07(1.03)$ & $6.39(0.91)$ & -4.02 & $<.001$ \\
\hline Goal Control & $1-7$ & 5.70 & $5.85(1.09)$ & $5.62(1.32)$ & 2.29 & .022 \\
\hline Goal Focus & $1-7$ & 5.63 & $5.52(1.15)$ & $5.69(1.28)$ & -1.71 & .088 \\
\hline Goal Distraction (Reverse) & $1-7$ & 3.55 & $3.20(1.53)$ & $3.74(1.81)$ & -3.78 & $<.001$ \\
\hline Perceived Partner Support & $1-7$ & 5.78 & $5.93(1.18)$ & $5.70(1.39)$ & 2.07 & .039 \\
\hline Goal Motivation & $1-7$ & 6.25 & $6.19(0.95)$ & $6.28(1.02)$ & -1.00 & .316 \\
\hline
\end{tabular}

Table 6.

Correlations between the attachment orientations, manipulation, and goal factors.

\begin{tabular}{|c|c|c|c|c|c|c|c|c|}
\hline & 1. & 2. & 3. & 4. & 5. & 6. & 7. & 8. \\
\hline 1. Attachment Anxiety & - & & & & & & & \\
\hline 2. Attachment Avoidance & $.32 * *$ & - & & & & & & \\
\hline 3. Manipulation & -.04 & $-.09 *$ & - & & & & & \\
\hline 4. Goal Control & $-.10 *$ & $-.10 *$ & $.08^{*}$ & - & & & & \\
\hline 5. Goal Focus & $-.18 * *$ & $-.22 * *$ & .06 & $.58 * *$ & - & & & \\
\hline 6. Goal Distraction & $.22 * *$ & $.09 *$ & -.03 & $-.16 * *$ & $-.29 * *$ & - & & \\
\hline 7. Partner Support & $-.12 * *$ & $-.35 * *$ & .07 & $.31 * *$ & $.46^{* *}$ & $-.11 * *$ & - & \\
\hline 8. Goal Motivation & $-.17 * *$ & $-.22 * *$ & .07 & $.42 * *$ & $.61^{* *}$ & $-.24 * *$ & $.45 * *$ & - \\
\hline
\end{tabular}


Manipulation check. In order to ensure the experimental manipulation led to changes in relationship satisfaction, a one-way ANOVA was conducted where current relationship satisfaction was compared as a function of the three conditions (positive scenario, negative scenario, and no scenario control condition). The results revealed that there was a significant effect of condition on current relationship satisfaction, $F(2,651)=16.56, p<.001$. There was a significant linear trend, $F(1,651)=28.98, p<.001$, indicating that current relationship satisfaction increased from the negative scenario condition to the positive scenario condition. Planned contrasts revealed that being in the negative scenario condition (weighted -1 ) significantly decreased relationship satisfaction when compared to the no scenario control condition (weighted +1$), t(651)=4.52, p<.001$. However, being in the positive scenario condition (weight +1 ) did not significantly increase relationship satisfaction when compared to the no scenario control condition (weighted -1$), t(651)=0.84, p=.401$. Planned contrasts also revealed that being in the positive scenario condition (weighted +1 ) significantly increased relationship satisfaction when compared to the negative scenario condition (weighted -1$), t(651)$ $=5.38, p<.001$.

\section{Hypothesis testing.}

Analysis plan. Similar to Study 1, before the main analyses were conducted, the two attachment subscales (i.e., attachment avoidance and attachment anxiety) were centered and the manipulation variable was dummy coded, such that the positive and negative scenario conditions were compared against the no-scenario control condition. Following these changes, the multiplicative interactions of the attachment subscales (centered) with the two dummy coded variables were obtained. To test whether the link between relationship satisfaction and goal pursuit differed as a function of attachment orientation, a series of moderated regression analyses was conducted. Similar to the analyses conducted in Study 1, both anxious attachment score 
(centered) and avoidant attachment scores (centered) were entered in order to control for the effects that each attachment orientation may have on the other. Significant interactions were plotted (using points 1SD above and below the anxious and avoidant attachment means) to facilitate interpretation.

Relationship satisfaction. To assess the extent to which attachment orientation moderated the effect of the manipulation on current relationship satisfaction, the single-item assessment of current relationship satisfaction was regressed on anxious attachment, avoidant attachment, the two dummy coded variables, as well as the interaction terms. As indicated earlier (manipulation check), a significant effect of the negative scenario relative to control $(b=-.68, p$ $<.001$ ) on relationship satisfaction was observed, but there was no effect of the positive scenario relative to control $(b=.01, p=.93)$. Those with an avoidant attachment orientation tended to report lower relationship satisfaction $(b=-.44, p<.001)$, as did those with an anxious attachment orientation (marginally, $b=-.15, p=.063$ ). Of the four interaction effects (positive and negative scenarios by anxious and avoidant attachment orientations), only the negative scenario by anxious attachment interaction was significant $(b=.21, p=.050)$. Specifically, for participants with low attachment anxiety reading the negative scenario significantly reduced current relationship satisfaction $(b=-.91, p<.001)$; the effect of reading the negative scenario on participants with high attachment anxiety was much weaker $(b=-.47, p=.006)$, although still significant. These results are presented in Figure 3. 


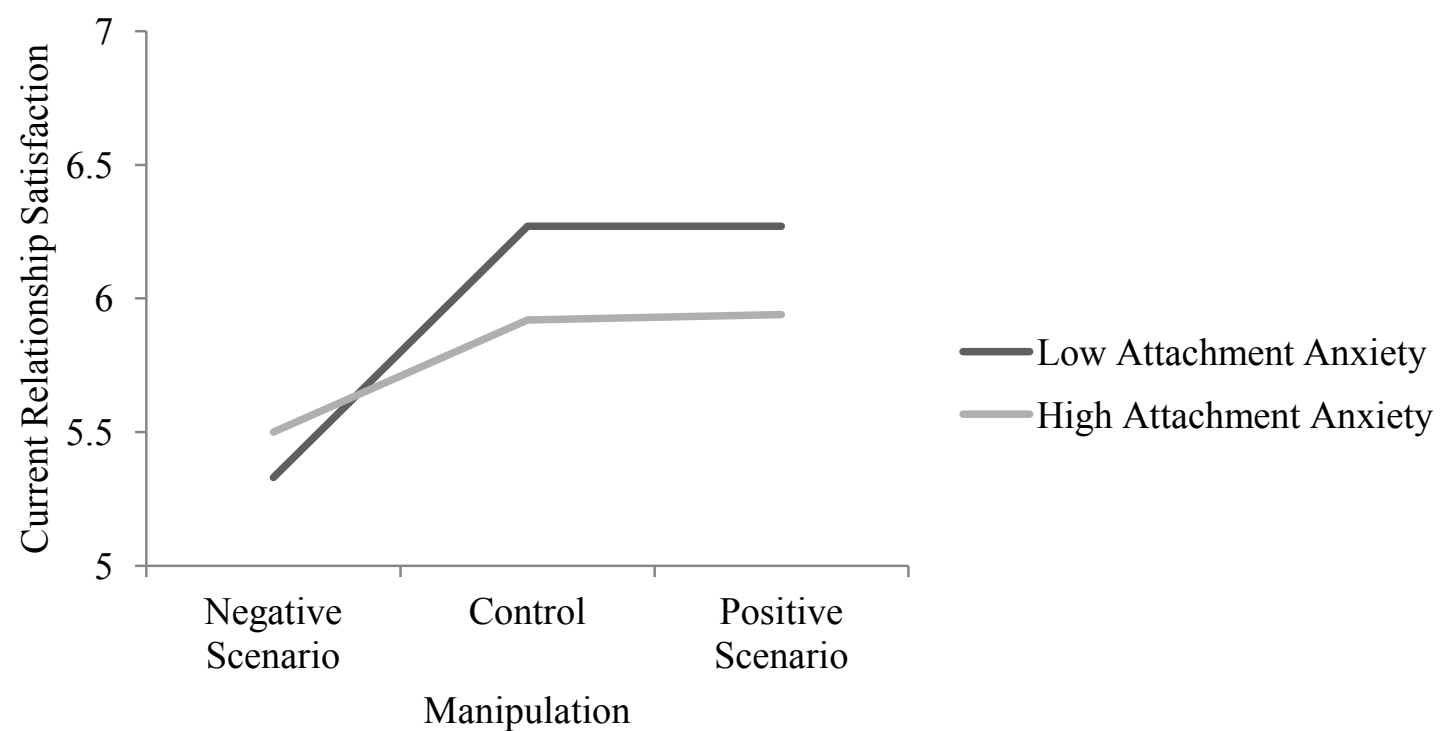

Figure 3. Graphical representation of the interaction of attachment anxiety scores by the manipulation on current relationship satisfaction.

Goal control and goal distraction. Except for a marginal effect of the positive scenario $(b=.23, p=.054)$, the relationship satisfaction manipulations had no significant main or interaction effects on goal control ( $p \mathrm{~s}>.15$, see Table 7). Likewise, the manipulations had no significant interaction effects on goal distraction $(p \mathrm{~s}>.25$, see Table 7). However, a significant main effect of attachment anxiety was observed for goal distraction, such that those scoring higher on attachment anxiety reported greater goal distraction $(b=.36, p<.001$, see Table 7$)$. Note that sample source was controlled for in these analyses as the samples differed significantly on goal control and distraction. 
Table 7.

Regression of Attachment and the Manipulation on Goal Control and Distraction in Study 2.

\begin{tabular}{|c|c|c|c|c|c|c|c|c|}
\hline \multirow[b]{2}{*}{ Predictor Variable } & \multicolumn{4}{|c|}{ Goal Control } & \multicolumn{4}{|c|}{ Goal Distraction } \\
\hline & $b$ & se & $t$ & $p$ & $b$ & se & $t$ & $p$ \\
\hline Positive Scenario Condition & .23 & .12 & 1.91 & .057 & -.08 & .16 & -0.51 & .61 \\
\hline Negative Scenario Condition & -.11 & .12 & -0.90 & .37 & .08 & .16 & 0.47 & .64 \\
\hline Attachment Anxiety & -.06 & .07 & -0.84 & .40 & .33 & .10 & 3.38 & .001 \\
\hline Attachment Avoidance & -.03 & .09 & -0.39 & .70 & .15 & .12 & 1.24 & .22 \\
\hline Anxiety $x$ Positive Scenario & -.15 & .11 & -1.39 & .17 & .06 & .14 & 0.43 & .67 \\
\hline Anxiety x Negative Scenario & .05 & .10 & 0.46 & .65 & -.16 & .14 & -1.13 & .26 \\
\hline Avoidance x Positive Scenario & -.03 & .13 & -0.20 & .84 & -.22 & .18 & -1.17 & .24 \\
\hline Avoidance $\mathrm{x}$ Negative Scenario & -.06 & .12 & -0.54 & .60 & -.08 & .16 & -0.47 & .64 \\
\hline Sample (MTurk) & -.21 & .10 & -2.05 & .041 & -.52 & .14 & -3.72 & $<.001$ \\
\hline
\end{tabular}

Note: For Sample, $1=$ MTurk and $0=$ student sample. $N=654$.

Goal focus. The positive and negative scenarios did not have significant main effects on goal focus, but the effect of the negative scenario was moderated by anxious attachment $(b=.22$, $p=.020$, see Table 8$)$, which had a direct, main effect on goal focus $(b=-.22, p=.002)$. Simple effects on the significant interaction indicated that the negative scenario significantly reduced goal focus for those with low attachment anxiety $(b=-.36, p=.019)$, but not for those with high attachment anxiety $(b=.08, p=.624)$. These results are presented in Figure 4 .

Table 8.

Regression of Attachment and the Manipulation on Goal Focus in Study 2.

\begin{tabular}{lcccc}
\hline & \multicolumn{4}{c}{ Goal Focus } \\
\cline { 2 - 5 } Predictor Variable & $b$ & $s e$ & $t$ & $p$ \\
Positive Scenario Condition & .10 & .12 & 0.90 & .37 \\
Negative Scenario Condition & .13 & .12 & -1.15 & .25 \\
Attachment Anxiety & $\mathbf{- . 2 2}$ & $\mathbf{. 0 7}$ & $\mathbf{- 3 . 1 5}$ & $\mathbf{. 0 0 2}$ \\
Attachment Avoidance & -.14 & .08 & -1.67 & .10 \\
Anxiety x Positive Scenario & .05 & .10 & 0.53 & .60 \\
Anxiety x Negative Scenario & $\mathbf{. 2 2}$ & $\mathbf{. 1 3}$ & $\mathbf{2 . 2 4}$ & $\mathbf{. 0 2 0}$ \\
Avoidance x Positive Scenario & -.10 & .13 & -0.76 & .45 \\
Avoidance x Negative Scenario & -.13 & .12 & -1.11 & .27 \\
\hline
\end{tabular}

Note: For Sample, $1=$ MTurk and $0=$ student sample. $N=654$. 


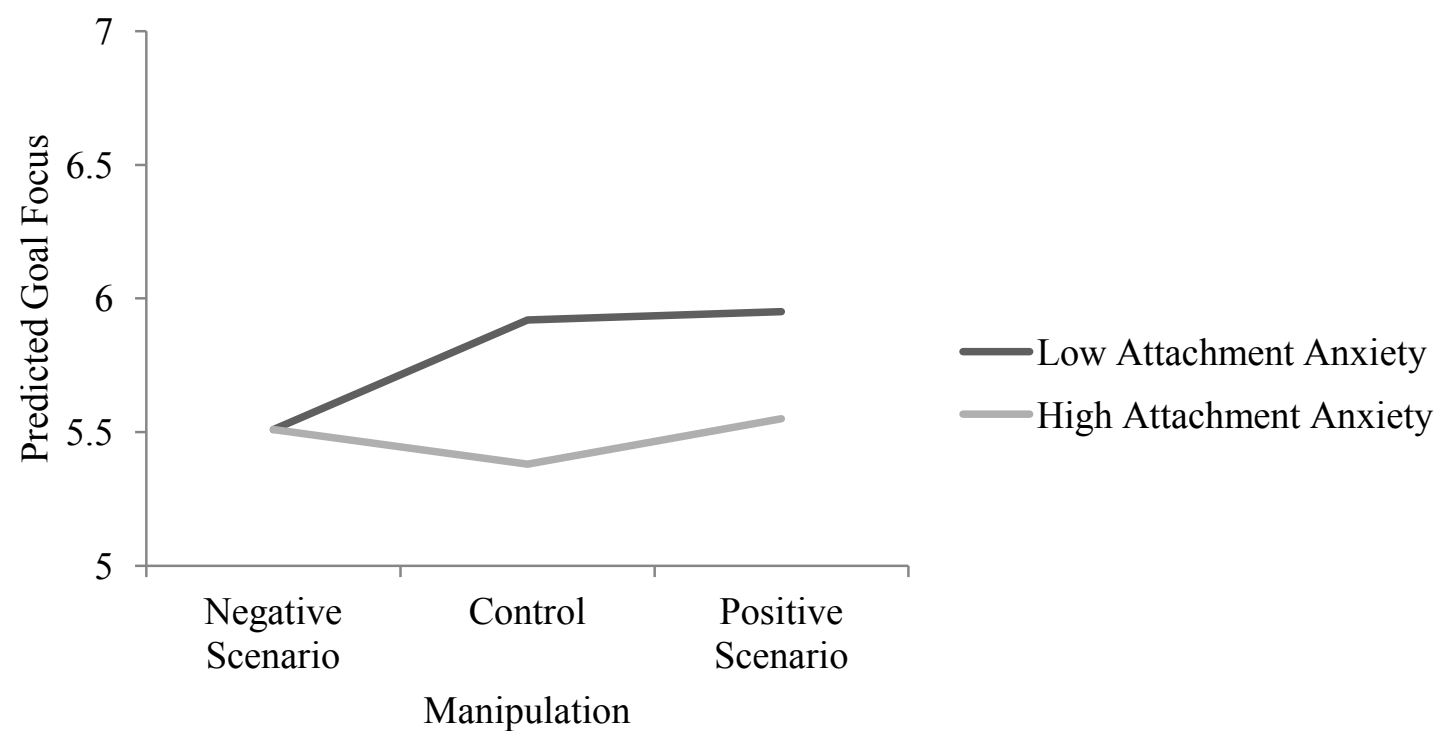

Figure 4. Graphical representation of the interaction of attachment anxiety scores by the manipulation on predicted goal focus.

Perceived partner support. The positive scenario had no significant effect on perceived partner support $(b=.14, p=.24)$. Relative to the control condition, the negative scenario resulted in marginally lower perceived partner support $(b=-.21, p=.078)^{1}$. This marginal effect was qualified by a marginally significant negative scenario by anxious attachment interaction $(b=$ $.19, p=.063)$. Similar to findings for goal focus, reading the negative scenario significantly reduced perceived partner support relative to controls for those with low attachment anxiety $(b=$ $-.42, p=.007)$, but not for those with high attachment anxiety $(b=-.02, p=.904)$. These results are presented in Figure 5. In addition to these effects, we also observed that those scoring higher on attachment avoidance tended to report lower partner support $(b=-.39, p<.001)$. The results of these analyses are detailed in Table 9. Note that sample source was controlled for in these analyses as the samples differed significantly on perceived partner support. 


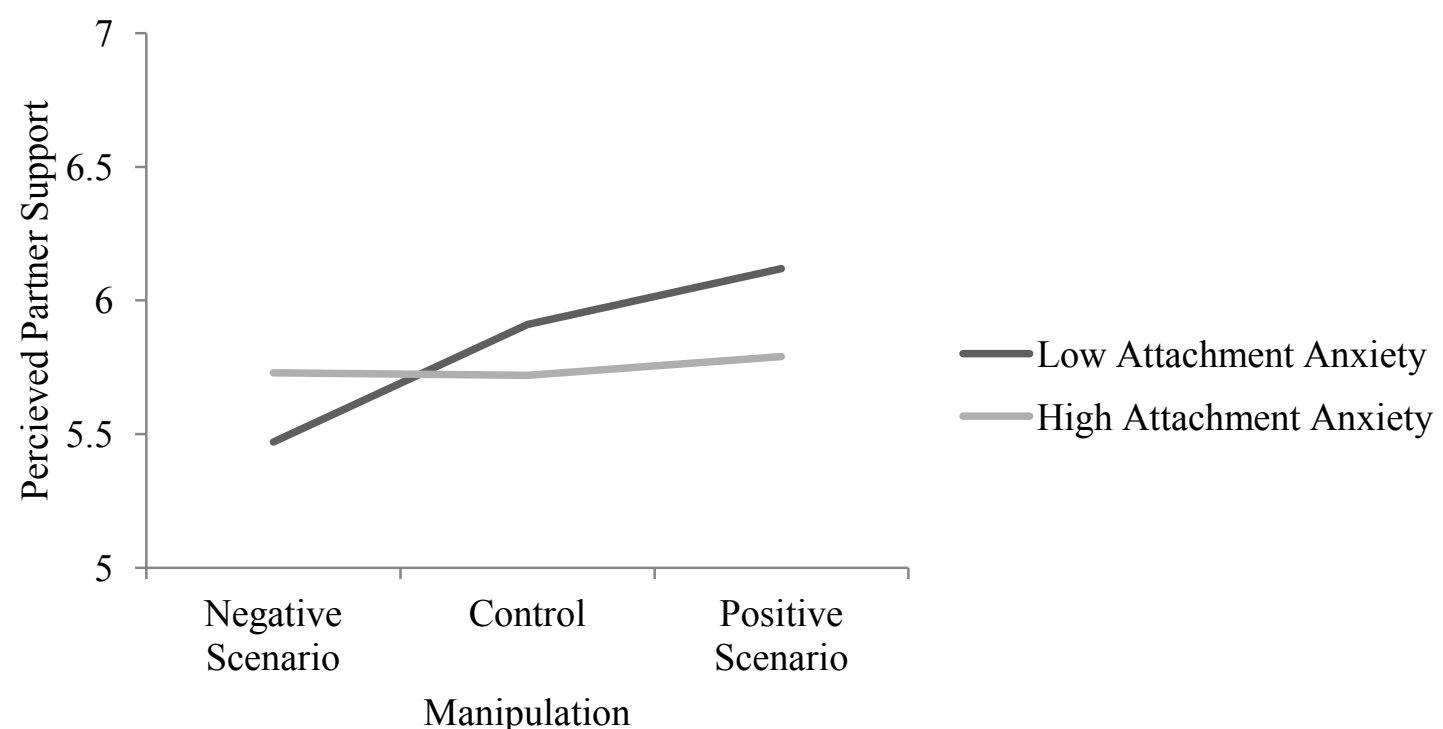

Figure 5. Graphical representation of the interaction of attachment anxiety scores by the manipulation on perceived partner support.

Goal motivation. Relative to the control group, those assigned to the positive scenario reported slightly, but not significantly, more goal motivation $(b=.11, p=.24)$ and those assigned to the negative scenario condition reported a modest decrease in goal motivation that was also not significant $(b=-.12, p=.20)^{2}$. Also, significant main effects of anxious and avoidant attachment orientation were observed, such that those scoring low on each orientation reported greater goal motivation $(b=-.18, p=.002$, and $b=-.14, p=.034$, respectively). Moreover, similar to perceived partner support, the negative scenario by anxious attachment interaction was significant $(b=.12, p=.025)$. Similar to findings for both goal focus and perceived partner support, simple effects analyses indicated that the negative scenario significantly reduced goal motivation relative to controls for those with low attachment anxiety, $(b=-.30, p=.016)$, but not for those with high attachment anxiety $(b=.05, p=.664)$. These results are presented in Figure 6. See Table 9 for the detailed results of the regression analyses. 
Table 9.

Regression of Attachment and the Manipulation on Partner Support and Motivation in Study 2.

Predictor Variable

\begin{tabular}{lll}
\multicolumn{4}{c}{ Perceived Partner Support } \\
\hline$b$ & se $t$ & $p$
\end{tabular}

Positive Scenario Condition

$.14 \quad .12$

1.16

.25

$\mathbf{- 1 . 7 6} .079$

Negative Scenario Condition

$-.21$

.12

1.76

$-.09 \quad .07$

$-1.21$

.23

Attachment Avoidance

$-.38$

.09

$-4.39$

$<.001$

$-.05$

.11

$-0.48$

.63

Anxiety x Negative Scenario

$.19 \quad .10$

1.87

.063

Avoidance $\mathrm{x}$ Positive Scenario

.07

.14

0.48

.63

$-.19$

.12

$-1.54$

.13

$-.12 \quad .10$

$-1.19 \quad .234$

\begin{tabular}{cccc}
\multicolumn{4}{c}{ Goal Motivation } \\
\hline$b$ & $s e$ & $t$ & $p$ \\
.11 & .09 & 1.17 & .24 \\
-.12 & .09 & -1.28 & .20 \\
$\mathbf{- . 1 8}$ & $\mathbf{. 0 6}$ & $\mathbf{- 3 . 1 6}$ & $\mathbf{. 0 0 2}$ \\
$\mathbf{- . 1 4}$ & $\mathbf{. 0 7}$ & $\mathbf{- 2 . 1 2}$ & $\mathbf{. 0 3 4}$ \\
.08 & .08 & 1.00 & .32 \\
. $\mathbf{1 2}$ & $\mathbf{. 0 8}$ & $\mathbf{2 . 2 5}$ & $\mathbf{. 0 2 5}$ \\
-.10 & .12 & -0.98 & .33 \\
-.03 & .09 & -0.35 & .73 \\
& & &
\end{tabular}

Note: For Sample, $1=$ MTurk and $0=$ student sample. $N=654$.

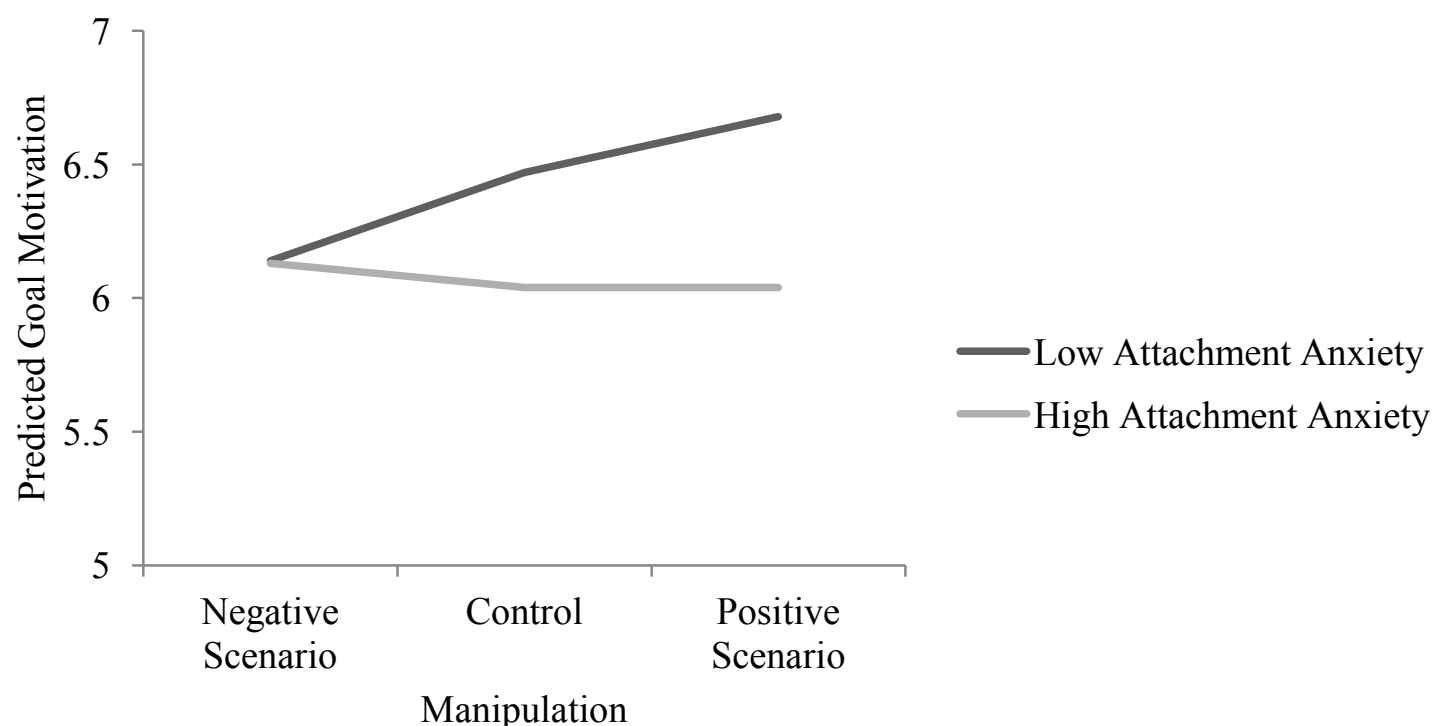

Figure 6. Graphical representation of the interaction of attachment anxiety scores by the manipulation on predicted goal motivation.

Mood restoration. To ensure that reading the positive scenario restored the mood of participants assigned to read the negative scenario, meant to momentarily decrease relationship satisfaction, an independent samples $t$-test was conducted comparing the current mood (collected at the end of the study) of participants assigned to read the negative and positive scenarios. The results revealed that after the mood restoration, participants assigned to read the positive scenario 
$(M=3.82, S D=1.19)$ were no longer significantly happier than participants assigned to read the negative scenario $(M=4.44, S D=.88), t(435)=6.21, p<.001$. These results indicate that the mood restoration was successful.

Secondary analyses. A number of secondary analyses were conducted to further examine the results found in Study 2. To begin, in order to examine the differences between the Mechanical Turk and Student samples, the data file was split according to sample source and a series of moderated regression analyses was conducted to test whether the link between relationship satisfaction and goal pursuit differed as a function of attachment orientation. The results from these analyses are presented in Appendix G. These results revealed inconsistent patterns across and between the two samples on all the key variables in the Study 2. For instance, when examining goal control there was a significant positive anxious attachment by negative scenario manipulation interaction found for the students sample, however, the effect of this same interaction in the Mechanical Turk sample was negatively weighted and no longer significant.

To ensure that the results of Study 2 were not affected by goal commitment and goal importance, the moderated regression analyses were re-run with goal importance and goal commitment included in the models. The results of these analyses are presented in Appendix H. These results revealed that attachment avoidance predicted significantly lower perceived partner support; anxious attachment significantly predicted lower goal focus and goal motivation, as well as more goal distraction. Further, reading the positive scenario predicted higher goal control, while reading the negative scenario marginally predicted lower perceived partner support and goal motivation. These main effects were consistent with those found in the main analyses of Study 2. However, the majority of the interaction effects found within the main analyses of Study 2 were no longer significant when goal importance and goal commitment were added into the model. The exception was the anxious attachment by negative scenario manipulation 
interaction on perceived partner support that remained marginally significant after controlling for goal importance and commitment.

To examine goal importance, participants who rated the identified goal to be very much important (6 on a 6-point Likert scale) were considered to have high goal importance $(n=568)$, while all other participants were considered to have low goal importance $(n=81)$. Following this categorization, the moderated regression analyses were re-run with the participants who were considered to have only high goal importance. The results of these analyses are presented in Appendix I. These results revealed that attachment avoidance predicted significantly lower relationship satisfaction, perceived partner support; anxious attachment significantly predicted lower goal focus and goal motivation, as well as more goal distraction. Further, reading the positive scenario predicted higher goal control, while reading the negative scenario marginally predicted lower perceived partner support. These main effects were similar to those found in the main analyses of Study 2. Further, two interaction effects were found to be significant indicating that anxious attachment interacted with the negative scenario manipulation to predict goal focus and goal motivation. These two interaction effects are consistent with those found in the main analyses of Study 2.

Finally, to compare the results found in Study 2 with those found in Study 1, the control condition was removed from Study 2 by contrast coding the manipulation variable so that those who read the negative scenario meant to decrease relationship satisfaction were coded as -1 and those who read the positive scenario meant to increase relationship satisfaction were coded as 1 . Following these changes, the multiplicative interactions of each attachment subscale with the contrast coded manipulation variable were obtained. To test whether the link between relationship satisfaction and goal pursuit differed as a function of attachment orientation, a series of moderated regression analyses was conducted. The results of these analyses are presented in 
Appendix J. These results revealed that attachment avoidance predicted significantly lower relationship satisfaction, goal focus, perceived partner support, and goal motivation; anxious attachment significantly predicted lower goal control and more goal distraction. Further, reading the positive scenario predicted higher relationship satisfaction, goal focus, and goal motivation, as well as significantly less goal distraction. The only significant interaction effect indicated anxious attachment interacted with the manipulation to predict perceived partner support. These results were fairly consistent with those found in Study 1.

\section{Discussion}

This study examined the extent to which attachment orientation moderated the effect of relationship satisfaction on the pursuit of long-term goals. Unlike Study 1, this study found that attachment orientation was a significant moderator for the effect of relationship satisfaction on a number of goal-related factors, including goal focus, perceived partner support, and goal motivation. However, these effects were inconsistent with those that were hypothesized. Specifically, although it was anticipated that individuals with high attachment anxiety would be more affected by the manipulation than those with low attachment anxiety, the results indicated that reading the negative scenario predicted lower goal focus, perceived partner support, and goal motivation only for those lower attachment anxiety; for those with a highly anxious attachment orientation, the negative scenario had no effect on relationship satisfaction, goal focus, perceived partner support and goal motivation. This puzzling set of results might be due to the possibility that for those with a highly anxious attachment orientation, the manipulation failed to activate the attachment system because for these individuals, the attachment system is chronically activated. It has been previously established that individuals with an anxious attachment orientation have the tendency to worry about romantic relationships (Brennan et al., 1998; Fraley \& Shaver, 2000; Hazan \& Shaver, 1994), and consequently report lower levels of relationship 
satisfaction when compared to those with lower attachment anxiety (Kirkpatrick \& Davis, 1994). This low relationship satisfaction can activate the attachment system, which motivates these individuals to engage in hyperactivating strategies that prevent one from feeling safe enough to freely explore personal interests (Bowlby, 1988; Grossmann, Grossmann, \& Zimmerman, 1999). Thus, individuals with a more anxious attachment orientation may consistently show low levels of goal pursuit, regardless of fluctuations in relationship satisfaction. In contrast, individuals with a more secure orientation (i.e., low attachment anxiety and low attachment avoidance) have the tendency to feel at ease with autonomy (Brennan et al., 1998; Fraley \& Shaver, 2000; Hazan \& Shaver, 1994) leading these individuals to report higher levels of relationship satisfaction, when compared to those with an insecure attachment orientation (Kirkpatrick \& Davis, 1994). This allows these individuals to freely explore personal interests when no stressor is present (Bowlby, 1969; Mikulincer \& Shaver, 2016). However, when a stressor, such as diminished relationship satisfaction, is present these individuals momentarily shift focus away from personal interests to ensure that one's partner is available and attentive (Mikulincer \& Shaver, 2016). The effect of this shift in focus for those with low attachment anxiety is evident in the results of the current study, which suggest that diminishing relationship satisfaction in those with low attachment anxiety may inhibit goal pursuits.

In addition to these moderation effects, there were a number of main effects of attachment orientation on the goal-related factors. Specifically, people with higher levels of attachment anxiety tended to report lower goal focus and goal motivation, as well as more goal distraction; those with higher attachment avoidance tended to report lower perceived partner support and goal motivation. These results are consistent with previous research suggesting that people who possess a more anxious attachment orientation tend to engage in hyperactivating strategies, which prioritize seeking comfort from a partner, resulting in these individuals shifting 
focus away from nonattachment related activities, such as personal goal pursuits (Elliot \& Reis, 2003; Mikulincer \& Shaver, 2016). Likewise, people who display a more avoidant attachment orientation tend to enact deactivating strategies, which prioritize self-reliance through distancing, leading these individuals to hold more negative and critical views of a romantic partner (Campbell et al., 2005; Mikulincer \& Shaver, 2016; Simpson et al., 1992).

In Study 1, the manipulation of relationship satisfaction influenced the extent to which the participants perceived partner support and felt positive affect. However, because Study 1 (and Hofmann, et al., 2015) did not include a no-manipulation control group, it was not clear whether increasing relationship satisfaction facilitated these goal pursuit factors or whether decreasing relationship satisfaction inhibited these factors. Thus, in Study 2 a no-manipulation control group was added to the manipulation of relationship satisfaction to assess whether increasing relationship satisfaction had a facilitation effect or whether decreasing relationship satisfaction had an inhibition effect on goal pursuit. Although Hofmann et al. (2015) did not include a no-manipulation control group, the researchers asserted that relationship satisfaction had a facilitation affect on goal pursuit. However, the results of Study 2 revealed that increasing relationship satisfaction did not facilitate goal pursuit, but instead that decreasing relationship satisfaction inhibited goal pursuit. Despite the assertion made by Hofmann et al. (2015), the results of Study 2 are consistent with past research examining the differential impacts of positive and negative events. This research indicates that negative events generally have greater impact on one's behavior and cognitions than positive events (for review see Baumeister, Bratslavsky, Finkenauer, \& Vohs, 2001). Thus, it is reasonable that in this study reading a negative scenario had inhibiting effects on goal pursuit, while reading a positive scenario had no facilitating effects.

\section{General Discussion}


The current research examined how attachment orientation moderates the effect of relationship satisfaction on the pursuit of goals. Study 2 examined the extent to which attachment orientation moderated the effect of relationship satisfaction on the pursuit of long-term goals. The results indicated that attachment anxiety was a significant moderator for the effect of relationship satisfaction on a number of goal-related factors as those with a low attachment anxiety reported reduced goal focus, perceived partner support, and goal motivation after experiencing a decrease in relationship satisfaction. In addition, to assess whether increases and decreases in relationship satisfaction facilitated and inhibited goal pursuit, Study 2 included a nomanipulation control group. The results revealed that increases in relationship satisfaction did not facilitate goal pursuit, but decreases in relationship satisfaction did inhibit goal pursuit.

In contrast to Study 2, the findings of Study 1 indicated that those with low attachment avoidance predicted increased goal focus for fairly trivial, short-term goals following a positive relationship satisfaction manipulation. However, it is important to note the following limitations of the Study 1 methodology and results. Other than the aforementioned low attachment avoidance and goal focus finding, all other attachment moderations were not significant in Study 1. Further, unlike anxious attachment, avoidant attachment did not in fact predict lower relationship satisfaction following the negative relationship manipulation. Finally, the lack of a no-scenario control condition renders the interpretation of the positive scenario findings in Study 1 ambiguous. Taken together, these limitations suggest that Study 1 results indicate that attachment orientation was not a significant moderator for the association between relationship satisfaction and short-term goal pursuit, possibly due to the trivial nature of the identified shortterm goals.

In evaluating the direct and interactive effects that the attachment orientations and the manipulation of relationship satisfaction had on the goal-related factors, it is quite likely that 
some of the obtained effects were significant as a matter of chance, given the number of distinct statistical tests conducted. For instance, the interactions were no longer significant after a Bonferroni type correction using alpha levels of .01. However, in this general discussion of the studies, I have not focused on single results (whether statistically significant or not), but rather described general patterns such as decreases in relationship satisfaction (rather than increases) affected goal pursuit. Further, as the present research is the first of its kind to explore attachment as a moderator of relationship satisfaction, the use of a more generous alpha level may be warranted at this early stage.

Although promising results were found that indicate that attachment orientation moderates the effect of relationship satisfaction on long-term goal pursuit, the limitations of the current studies should not be overlooked. For instance, to improve the generalizability of the anticipated effects, data were collected from two sources (i.e., the subject pool in the Psychology department of a large Canadian university and Amazon's Mechanical Turk). Although this collection method was originally seen as a strength to the current research, the samples collected from these sources varied significantly in a number of the analyses. Thus, future research should consider collecting large enough samples from each of these sources in order to examine each sample separately. It is concerning that in both studies the manipulation did not have an effect on a number of the goal-related factors that were found in Hofmann et al. (2015). Within Study 1, the failure to replicate the manipulations effect on goal control and goal focus may have been due to the inconsequential short-term goals. However, this limitation was addressed in Study 2 and the failure to replicate the manipulation's effect on goal distraction, goal focus, and goal motivation remained in this study ${ }^{3}$. This failure to replicate the effect of the manipulation may not be due to any specific limitations of the current studies, but may instead reflect a budding issue in psychology as a whole: the reproducibility of psychological research (Open Science 
Collaboration, 2015). This dilemma was brought to the attention of researchers after a recent study conducted the replications of 100 experimental and correlational studies. This study found that a large portion of the replications showed weaker effects than the original findings despite using the materials provided by the original authors (Open Science Collaboration, 2015). Unfortunately, this discussion is beyond the scope of the current research; however, for further information regarding this issue see "Estimating the reproducibility of psychological science" (Open Science Collaboration, 2015).

The present research is part of an emerging theme in relationship research attempting to understand how romantic relationships and self-regulation interact; therefore, there are many avenues for improvement and growth in this area of research. As noted above, future research can improve the present studies by addressing some of the outstanding limitations, but growth in this area of relationship research is also possible. For instance, future research may want to consider how the results differ according to goal type (e.g., health goals, relationship goals, occupational goals), as some goals may be more affected by decreases in relationship satisfaction than others. Also, there is a reciprocal dynamic in romantic relationships where the behaviours of one partner may impact the behaviours and cognitions of the other partner. Hence, future research may consider examining how various relationship behaviours (e.g., support seeking, partner responsiveness, care giving) and dyadic processes alter the link between relationship satisfaction and goal pursuits. Finally, a number of personality factors, apart from attachment orientation, may moderate the link between relationship satisfaction and goal pursuit. For example, exhibiting high levels of neuroticism may heighten the unpleasantness of diminishing relationship satisfaction resulting in lower levels of goal pursuit. Because this is a recent area of relationship research, there are many avenues for growth as it is still fairly unknown how our relationships can promote or hinder our personal goal pursuits. 


\section{Conclusions}

In conclusion, the present research provides some insight into how our romantic relationships influence our goal pursuits. Specifically, fluctuations in relationship satisfaction do not appear to affect the goal pursuits of individuals with more anxious and avoidant attachment orientations. However, for those with low attachment anxiety, dissatisfaction in a romantic relationship diminishes goal focus, perceived partner support, and goal motivation towards longterm goal pursuits, but appear not to affect short-term goals that are fairly easy to accomplish. Thus, maintaining relationship satisfaction may be important both for preserving romantic relationships and supporting more personal endeavours, such as long-term goal pursuit. 


\section{References}

Bartholomew, K., \& Horowitz, L. M. (1991). Attachment styles among young adults: A test of a four-category model. Journal of Personality and Social Psychology, 61, 226-244.

Bowlby, J. (1969). Attachment and loss. Volume 1: Attachment. London, UK: Basic Books.

Bowlby, J. (1988). A secure base: Parent-child attachment and healthy human development. New York, NY: Basic Books.

Brennan, K. A., Clark, C. L., \& Shaver, P. R. (1998). Self-report measurement of adult romantic attachment: An integrative overview. In J. A. Simpson \& W. S. Rholes (Eds.), Attachment theory and close relationships (pp. 46-76). New York: Guilford Press

Campbell, L., \& Marshall, T. (2011). Anxious attachment and relationship processes: An interactionist perspective. Journal of Personality, 79(6), 1219-1250. doi: 10.1111/j.14676494.2011.00723.x

Campbell, L., Simpson, J. A., Boldry, J., \& Kashy, D. A. (2005). Perceptions of conflict and support in romantic relationship: The role of attachment anxiety. Journal of Personality and Social Psychology, 88(3), 510-531. doi: 10.1037/0022-3514.88.3.510

Elliot, A. J., \& Reis, H. T. (2003). Attachment and exploration in adulthood. Journal of Personality and Social Psychology, 85(2), 317-331. doi: 10.1037/0022-3514.85.2.317

Emmons, R. A. (1997). Motives and goals. In R. Hogan, J. Johnson, \& S. Briggs (Eds), Handbook of personality psychology (pp. 485-512). New York, NY: Academic Press.

Fraley, R. C. (2002). Attachment stability from infancy to adulthood: Meta-analysis and dynamic modeling of developmental mechanisms. Personality and Social Psychology Review, 6, 123-151. doi:10.1207/S15327957PSPR0602_03 
Fraley, R. C., \& Shaver, P. R. (2000). Adult romantic attachment: Theoretical developments, emerging controversies, and unanswered questions. Review of General Psychology, 4, 132154. doi:10.1037/1089-2680.4.2.132

Grossmann, K. E., Grossmann, K., \& Zimmermann, P. (1999). A wider view of attachment and exploration: Stability and change during the years of immaturity. In J. Cassidy \& P. R. Shaver (Eds.), Handbook of attachment: Theory, research, and clinical applications (pp. 760-786). New York, NY: Guilford Press.

Hazan, C., \& Shaver, P. R. (1994). Attachment as an organizational framework for research on close relationships. Psychological Inquiry, 5, 1, 1-22. doi:10.1207/s15327965pli0501_1

Hofmann, W., Finkel, E.J., \& Fitzsimons, G.M. (2015). Close relationships and selfregulation: How relationship satisfaction facilitates momentary goal pursuit. Journal of Personality and Social Psychology. 109(3), 434-452. doi: 10.1037/pspi0000020

Kirkpatrick, L. A., \& Davis, K. E. (1994). Attachment style, gender, and relationship stability: A longitudinal analysis. Journal of Personality and Social Psychology, 66(3), 502-512

Love, A. B., \& Holder, M. D. (2015). Can romantic relationship quality mediate the relation between psychopathy and subjective well-being? Journal of Happiness Studies, 1-23. doi:10.1007/s10902-015-9700-2

Mikulincer, M., \& Shaver, P. R. (2003). The attachment behavioral system in adulthood: Activation, psychodynamics, and interpersonal processes. In M. Zanna (Ed.), Advances in experimental social psychology (Vol. 35). New York, NY: Academic Press.

Mikulincer, M., \& Shaver, P. R. (2016). Attachment in adulthood: Structure, dynamics and change (2nd ed.). New York, NY: Guilfold Press. 
Open Science Collaboration. (2015). Estimating the reproducibility of psychological science. Science, 349(6251). doi:10.1126/science.aac4716

Rusbult, C. E., Martz, J. M., \& Agnew, C. R. (1998). The investment model scale: Measuring commitment level, satisfaction level, quality of alternatives, and investment size. Personal Relationships, 5, 357-391. doi: 10.1111/j.1475-6811.1998.tb00177.x

Shaver, P. R., \& Mikulincer, M. (2002). Attachment-related psychodynamics. Attachment and Human Development, 4, 133-161.

Shaver, P. R., \& Mikulincer, M. (2007). Adult attachment strategies and the regulation of emotion. In J. J. Gross (Ed.), Handbook of emotion regulation (pp. 446-465). New York: Guilford Press.

Simpson, J. A., Rholes, W. S., \& Nelligan, J. S. (1992). Support seeking and support giving within couples in an anxiety-provoking situation: The role of attachment styles. Journal of Personality and Social Psychology, 62, 434-446. doi:10.1037/0022-3514.62.3.434

Simpson, J. A., Rholes, W. S., \& Phillips, D. (1996). Conflict in close relationships: An attachment perspective. Journal of Personality and Social Psychology, 71, 899-914. doi:10.1037/0022-3514.71.5.899

Wei, M., Russell, D. W., Mallinckrodt, B., \& Vogel, D. L. (2007). The experiences in Close Relationship Scale (ECR)-Short Form: Reliability, validity, and factor structure. Journal of Personality Assessment, 88(2), 187-204. doi:10.1080/00223890701268041 


\section{Footnotes}

${ }^{1}$ For perceived partner support, when comparing the negative scenario (coded 0) directly to the positive scenario (coded 1$)$, the effect of the manipulation was significant $(b=.35, p=.003)$. This indicates that the experimental manipulation of relationship satisfaction was successful. ${ }^{2}$ As was the case with perceived partner support, the difference between the positive scenario condition and the negative scenario condition was significant $(b=.23, p=.015)$ for goal motivation. Thus, the experimental manipulation of relationship satisfaction was successful.

${ }^{3}$ When the control group was removed from Study 2, the manipulation failed to have an effect on goal control and perceived partner support (see Appendix $\mathrm{J}$ for results). 


\section{Appendix A}

\section{Demographics}

First, we would like to gather some demographic information. All information you provide will be completely confidential and will not be associated in any way with your identity. Please answer the questions below.

1. What is your gender? $\quad$ Female

2. What is your Age: (in years)

3. What is your current "relationship status"?

a) Single, not dating (if this is endorsed, participant skips out of the study)

b) Single, casually dating

c) In a serious dating relationship

d) In a serious dating relationship and living together

e) In a serious dating relationship, living together, and engaged

f) Married

g) Common-law

h) Other (please specify):

4. If you are in a relationship, do you consider it a long-distance relationship? Yes No

5. If you are in a relationship, please estimate approximately how long (in years/months) you have been involved with your partner: years and months

6. Please indicate the initials of your partner here:

7. Please indicate how committed you are to your romantic relationship:

1

Not at all

Committed

\section{2}

4

Somewhat

Committed

56

6 7 Very Committed 


\section{Appendix B}

\section{Experiences in Close Relationship Scale - Short Form}

Instruction: The following statements concern how you feel in romantic relationships. We are interested in how you generally experience relationships, not just in what is happening in a current relationship. Respond to each statement by indicating how much you agree or disagree with it. Mark your answer using the following rating scale:

\begin{tabular}{|c|c|c|c|c|c|c|}
\hline 1 & 2 & 3 & 4 & 5 & 6 & 7 \\
\hline $\begin{array}{c}\text { Strongly } \\
\text { disagree }\end{array}$ & Disagree & $\begin{array}{c}\text { Slightly } \\
\text { Disagree }\end{array}$ & Neutral & $\begin{array}{c}\text { Slightly } \\
\text { Agree }\end{array}$ & Agree & $\begin{array}{c}\text { Strongly } \\
\text { Agree }\end{array}$ \\
\hline
\end{tabular}

1. It helps to turn to my romantic partner in times of need.

2. I need a lot of reassurance that I am loved by my partner.

3. I want to get close to my partner, but I keep pulling back.

4. I find that my partner(s) don't want to get as close as I would like.

5. I turn to my partner for many things, including comfort and reassurance.

6. My desire to be very close sometimes scares people away.

7. I try to avoid getting too close to my partner.

8. I do not often worry about being abandoned.

9. I usually discuss my problems and concerns with my partner.

10. I get frustrated if romantic partners are not available when I need them.

11. I am nervous when partners get too close to me.

12. I worry that romantic partners won't care about me as much as I care about them. 


\section{Appendix C}

\section{Goal Identification}

Think of an important goal that you intend to complete over the next few months. For example, the goal might be to finish a significant project for work, to plan a vacation, or to get in shape or quit smoking. It could be any nontrivial goal from any sphere in your life. Please do not mention the goal of completing this survey; instead, please think of a goal that is going to take you some time to complete.

Please describe the goal:

How important is this goal to you?
0
1
2
3
4
5
6

Not at all

Important

How difficult is this goal for you to achieve?

0

Not at all

Difficult
23

12

4

5

\section{Very Difficult}

How committed are you to achieving this goal?

0

1

2

3

Not at all

4

5

6

Very Committed 


\section{Appendix D}

\section{Relationship Satisfaction Manipulation}

\section{Condition 1 (High Relationship Satisfaction Condition):}

Imagine for a few minutes that you surprise your partner with reservations for a romantic weekend together. Take a minute to imagine where you would go (e.g., a cabin in Vermont), what you would like to do (e.g., ski, dine, hot-tub, and then curl up in front of fireplace), and the look on your partner's face when you surprise them with the reservations.

Please indicate which of the following facial expressions best captures the feeling you have as you think about this weekend that you have planned.

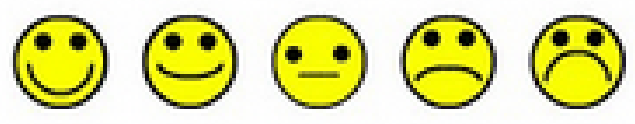

\section{Condition 2 (Low Relationship Satisfaction Condition):}

Imagine for a few minutes that you come home early from a trip away, planning to surprise your partner and find your partner in bed with your best friend. You confront your partner who says they were going to tell you when you returned from your trip that they were planning to leave you for your best friend. Take a minute to imagine the look on their faces when you discover them in bed together, and how you would confront both of them.

Please indicate which of the following facial expressions best captures the feeling you have as you think about this situation.

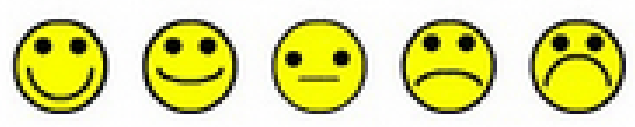

\section{Control Condition Skips the Manipulation}

\section{Manipulation Check (All Participants)}

Please indicate how satisfied you are with your relationship with your partner at the current moment
1
2
3
4
5
6
7

Not at All

Somewhat

Very

Satisfied

Satisfied

Satisfied 


\section{Appendix E}

\section{Pursuit of Goals}

Thinking back to the goal you described earlier (a goal that you indicated that you intended to complete today or tomorrow), please rate the following:

1. How much do you feel in control over accomplishing this?

$\begin{array}{ccccccc}0 & 1 & 2 & 3 & 4 & 5 & 6 \\ \text { Not at all } & & & & & & \text { Very Much }\end{array}$

2. How much do you think you will be able to focus on getting this done?
Not at all
2
3
4
5
6
Very Much

3. How much do you think you will be mentally distracted by other things when trying to get this done?
0
1
2
3
4
5
6
Not at all Very Much

4. How supportive or unsupportive do you feel your partner will be in your pursuit of this?

$\begin{array}{llllllc}-3 & -2 & -1 & 0 & 1 & 2 & +3 \\ \text { Very Unsupportive }^{-2} & & & & & \text { Very Supportive }\end{array}$

5. How much do you think your partner will make it easier or more difficult for you to accomplish this?

$-3$

$-2$

More Difficult $\begin{array}{ll}-1 & 0\end{array}$

1

6. How happy do you feel at this moment?

Very Unhappy

$-1 \quad 0$

0

(1)

7. How motivated are you to accomplish this?

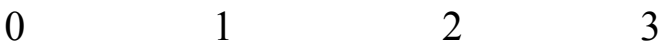

Not at all

3
4 Very Much

8. How much effort are you willing to invest in realizing this goal?

0

1

2

3

4

Not at all
2

$+3$

Easier 


\section{Appendix F}

\section{Mood Restoration}

Imagine for a few minutes that you surprise your partner with reservations for a romantic weekend together. Take a minute to imagine where you would go (e.g., a cabin in Vermont), what you would like to do (e.g., ski, dine, hot-tub, and then curl up in front of fireplace), and the look on your partner's face when you surprise them with the reservations.

Please indicate which of the following facial expressions best captures the feeling you have as you think about this weekend that you have planned.

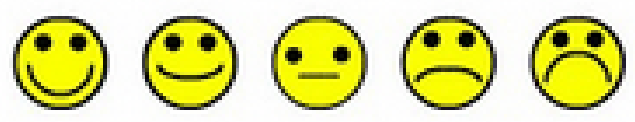




\section{Appendix G}

Table 10

Moderated Regression Analyses of Relationship Satisfaction Separated by Sample

\begin{tabular}{|c|c|c|c|c|c|}
\hline Sample & Variables & $B$ & $S E$ & $t$ & $p$ \\
\hline Student & (Constant) & 6.07 & 0.12 & 50.31 & $<.001$ \\
\hline \multirow[t]{8}{*}{$d f=220$} & Anxious Attachment Score (Centered) & -0.01 & 0.12 & -0.06 & .955 \\
\hline & Avoidant Attachment Score (Centered) & -0.45 & 0.14 & -3.36 & .001 \\
\hline & Negative Scenario Condition & -0.34 & 0.17 & -1.98 & .049 \\
\hline & Positive Scenario Condition & 0.04 & 0.17 & 0.26 & .798 \\
\hline & $\begin{array}{l}\text { Anxious Attachment by Negative Scenario } \\
\text { Interaction }\end{array}$ & -0.16 & 0.17 & -0.96 & .338 \\
\hline & $\begin{array}{l}\text { Anxious Attachment by Positive Scenario } \\
\text { Interaction }\end{array}$ & -0.30 & 0.17 & -1.77 & .078 \\
\hline & $\begin{array}{l}\text { Avoidant Attachment by Negative Scenario } \\
\text { Interaction }\end{array}$ & -0.39 & 0.19 & -2.05 & .042 \\
\hline & $\begin{array}{l}\text { Avoidant Attachment by Positive Scenario } \\
\text { Interaction }\end{array}$ & 0.13 & 0.21 & 0.64 & .525 \\
\hline $\begin{array}{l}\text { Mechanical } \\
\text { Turk }\end{array}$ & (Constant) & 6.10 & 0.12 & 49.30 & $<.001$ \\
\hline \multirow[t]{8}{*}{$d f=413$} & Anxious Attachment Score (Centered) & -0.20 & 0.10 & -1.96 & .051 \\
\hline & Avoidant Attachment Score (Centered) & -0.45 & 0.12 & -3.65 & $<.001$ \\
\hline & Negative Scenario Condition & -0.86 & 0.18 & -4.89 & \\
\hline & Positive Scenaris Condition & 002 & 017 & 010 & $\begin{array}{c}<.001 \\
017\end{array}$ \\
\hline & $\begin{array}{l}\text { Anxious Attachment by Negative Scenario } \\
\text { Interaction }\end{array}$ & 0.32 & 0.14 & 2.30 & .022 \\
\hline & $\begin{array}{l}\text { Anxious Attachment by Positive Scenario } \\
\text { Interaction }\end{array}$ & 0.13 & 0.15 & 0.87 & .387 \\
\hline & $\begin{array}{l}\text { Avoidant Attachment by Negative Scenario } \\
\text { Interaction }\end{array}$ & -0.01 & 0.17 & -0.05 & .958 \\
\hline & $\begin{array}{l}\text { Avoidant Attachment by Positive Scenario } \\
\text { Interaction }\end{array}$ & -0.09 & 0.19 & -0.49 & .622 \\
\hline
\end{tabular}


Table 11

Moderated Regression Analyses of Goal Control Separated by Sample

\begin{tabular}{|c|c|c|c|c|c|}
\hline Sample & Variables & $B$ & $S E$ & $t$ & $p$ \\
\hline Student & (Constant) & 5.93 & 0.13 & 47.57 & $<.001$ \\
\hline \multirow[t]{8}{*}{$d f=220$} & Anxious Attachment Score (Centered) & -0.20 & 0.02 & -1.65 & .100 \\
\hline & Avoidant Attachment Score (Centered) & -0.18 & 0.14 & -1.27 & .207 \\
\hline & Negative Scenario Condition & -0.32 & 0.18 & -1.82 & .071 \\
\hline & Positive Scenario Condition & 0.02 & 0.17 & 0.12 & .914 \\
\hline & $\begin{array}{l}\text { Anxious Attachment by Negative Scenario } \\
\text { Interaction }\end{array}$ & 0.38 & 0.17 & 2.22 & .028 \\
\hline & $\begin{array}{l}\text { Anxious Attachment by Positive Scenario } \\
\text { Interaction }\end{array}$ & -0.03 & 0.18 & -0.17 & .867 \\
\hline & $\begin{array}{l}\text { Avoidant Attachment by Negative Scenario } \\
\text { Interaction }\end{array}$ & -0.33 & 0.20 & -1.65 & .100 \\
\hline & $\begin{array}{l}\text { Avoidant Attachment by Positive Scenario } \\
\text { Interaction }\end{array}$ & 0.21 & 0.21 & 0.99 & .336 \\
\hline MTurk & (Constant) & 5.50 & 0.11 & 49.42 & $<.001$ \\
\hline \multirow[t]{8}{*}{$d f=413$} & Anxious Attachment Score (Centered) & -0.01 & 0.09 & -0.12 & .902 \\
\hline & Avoidant Attachment Score (Centered) & 0.06 & 0.11 & 0.55 & .582 \\
\hline & Negative Scenario Condition & -0.04 & 0.16 & -0.23 & .817 \\
\hline & Positive Scenario Condition & 0.36 & 0.16 & 2.28 & .023 \\
\hline & $\begin{array}{l}\text { Anxious Attachment by Negative Scenario } \\
\text { Interaction }\end{array}$ & -0.06 & 0.13 & -0.48 & .629 \\
\hline & $\begin{array}{l}\text { Anxious Attachment by Positive Scenario } \\
\text { Interaction }\end{array}$ & -0.18 & 0.13 & -1.39 & .165 \\
\hline & $\begin{array}{l}\text { Avoidant Attachment by Negative Scenario } \\
\text { Interaction }\end{array}$ & -0.01 & 0.15 & -0.10 & .924 \\
\hline & $\begin{array}{l}\text { Avoidant Attachment by Positive Scenario } \\
\text { Interaction }\end{array}$ & -0.17 & 0.17 & -1.01 & .311 \\
\hline
\end{tabular}


Table 12

Moderated Regression Analyses of Goal Focus Separated by Sample

\begin{tabular}{|c|c|c|c|c|c|}
\hline Sample & Variables & $B$ & $S E$ & $t$ & $p$ \\
\hline Student & (Constant) & 5.62 & 0.13 & 43.54 & $<.001$ \\
\hline \multirow[t]{8}{*}{$d f=220$} & Anxious Attachment Score (Centered) & -0.44 & 0.13 & -3.49 & .001 \\
\hline & Avoidant Attachment Score (Centered) & -0.15 & 0.14 & -1.02 & .310 \\
\hline & Negative Scenario Condition & -0.31 & 0.18 & -1.68 & .094 \\
\hline & Positive Scenario Condition & 0.01 & 0.18 & 0.07 & .946 \\
\hline & $\begin{array}{l}\text { Anxious Attachment by Negative Scenario } \\
\text { Interaction }\end{array}$ & 0.51 & 0.18 & 2.86 & .005 \\
\hline & $\begin{array}{l}\text { Anxious Attachment by Positive Scenario } \\
\text { Interaction }\end{array}$ & 0.15 & 0.18 & 0.81 & .416 \\
\hline & $\begin{array}{l}\text { Avoidant Attachment by Negative Scenario } \\
\text { Interaction }\end{array}$ & -0.15 & 0.20 & -0.74 & .459 \\
\hline & $\begin{array}{l}\text { Avoidant Attachment by Positive Scenario } \\
\text { Interaction }\end{array}$ & 0.01 & 0.22 & 0.05 & .959 \\
\hline MTurk & (Constant) & 5.68 & 0.11 & 53.38 & $<.001$ \\
\hline \multirow[t]{8}{*}{$d f=413$} & Anxious Attachment Score (Centered) & -0.13 & 0.09 & -1.56 & .120 \\
\hline & Avoidant Attachment Score (Centered) & -0.13 & 0.11 & -1.21 & .228 \\
\hline & Negative Scenario Condition & -0.07 & 0.15 & -0.43 & .667 \\
\hline & Positive Scenario Condition & 0.15 & 0.15 & 1.01 & .312 \\
\hline & $\begin{array}{l}\text { Anxious Attachment by Negative Scenario } \\
\text { Interaction }\end{array}$ & 0.13 & 0.12 & 1.05 & .293 \\
\hline & $\begin{array}{l}\text { Anxious Attachment by Positive Scenario } \\
\text { Interaction }\end{array}$ & 0.02 & 0.13 & 0.17 & .866 \\
\hline & $\begin{array}{l}\text { Avoidant Attachment by Negative Scenario } \\
\text { Interaction }\end{array}$ & -0.16 & 0.15 & -1.07 & .285 \\
\hline & $\begin{array}{l}\text { Avoidant Attachment by Positive Scenario } \\
\text { Interaction }\end{array}$ & -0.17 & 0.16 & -1.07 & .288 \\
\hline
\end{tabular}


Table 13

Moderated Regression Analyses of Goal Distraction Separated by Sample

\begin{tabular}{|c|c|c|c|c|c|}
\hline Sample & Variables & $B$ & $S E$ & $t$ & $P$ \\
\hline Student & (Constant) & 4.66 & 0.18 & 25.80 & $<.001$ \\
\hline \multirow[t]{8}{*}{$d f=220$} & Anxious Attachment Score (Centered) & 0.37 & 0.18 & 2.10 & .037 \\
\hline & Avoidant Attachment Score (Centered) & 0.09 & 0.20 & 0.45 & .653 \\
\hline & Negative Scenario Condition & 0.12 & 0.26 & 0.47 & .639 \\
\hline & Positive Scenario Condition & 0.21 & 0.25 & 0.82 & .413 \\
\hline & $\begin{array}{l}\text { Anxious Attachment by Negative Scenario } \\
\text { Interaction }\end{array}$ & -0.45 & 0.25 & -1.83 & .069 \\
\hline & $\begin{array}{l}\text { Anxious Attachment by Positive Scenario } \\
\text { Interaction }\end{array}$ & 0.08 & 0.25 & 0.30 & .766 \\
\hline & $\begin{array}{l}\text { Avoidant Attachment by Negative Scenario } \\
\text { Interaction }\end{array}$ & 0.14 & 0.29 & 0.49 & .627 \\
\hline & $\begin{array}{l}\text { Avoidant Attachment by Positive Scenario } \\
\text { Interaction }\end{array}$ & -0.18 & 0.31 & -0.59 & .553 \\
\hline MTurk & (Constant) & 4.31 & 0.15 & 28.60 & $<.001$ \\
\hline \multirow[t]{8}{*}{$d f=413$} & Anxious Attachment Score (Centered) & 0.33 & 0.12 & 2.74 & .006 \\
\hline & Avoidant Attachment Score (Centered) & 0.15 & 0.15 & 1.01 & .314 \\
\hline & Negative Scenario Condition & 0.10 & 0.21 & 0.45 & .650 \\
\hline & Positive Scenario Condition & -0.24 & 0.21 & -1.13 & .258 \\
\hline & $\begin{array}{l}\text { Anxious Attachment by Negative Scenario } \\
\text { Interaction }\end{array}$ & -0.06 & 0.17 & -0.35 & .730 \\
\hline & $\begin{array}{l}\text { Anxious Attachment by Positive Scenario } \\
\text { Interaction }\end{array}$ & 0.04 & 0.18 & 0.20 & .842 \\
\hline & $\begin{array}{l}\text { Avoidant Attachment by Negative Scenario } \\
\text { Interaction }\end{array}$ & -0.14 & 0.21 & -0.70 & .487 \\
\hline & $\begin{array}{l}\text { Avoidant Attachment by Positive Scenario } \\
\text { Interaction }\end{array}$ & -0.18 & 0.23 & -0.80 & .427 \\
\hline
\end{tabular}


Table 14

Moderated Regression Analyses of Partner Support Separated by Sample

\begin{tabular}{|c|c|c|c|c|c|}
\hline Sample & Variables & $B$ & $S E$ & $t$ & $p$ \\
\hline Student & (Constant) & 5.94 & 0.13 & 45.42 & $<.001$ \\
\hline \multirow[t]{8}{*}{$d f=220$} & Anxious Attachment Score (Centered) & -0.07 & 0.13 & -0.55 & .581 \\
\hline & Avoidant Attachment Score (Centered) & -0.40 & 0.15 & -2.72 & .007 \\
\hline & Negative Scenario Condition & -0.33 & 0.19 & -1.76 & .080 \\
\hline & Positive Scenario Condition & 0.15 & 0.18 & 0.80 & .424 \\
\hline & $\begin{array}{l}\text { Anxious Attachment by Negative Scenario } \\
\text { Interaction }\end{array}$ & 0.11 & 0.18 & 0.59 & .558 \\
\hline & $\begin{array}{l}\text { Anxious Attachment by Positive Scenario } \\
\text { Interaction }\end{array}$ & -0.22 & 0.18 & -1.20 & .232 \\
\hline & $\begin{array}{l}\text { Avoidant Attachment by Negative Scenario } \\
\text { Interaction }\end{array}$ & -0.31 & 0.21 & -1.51 & .132 \\
\hline & $\begin{array}{l}\text { Avoidant Attachment by Positive Scenario } \\
\text { Interaction }\end{array}$ & 0.35 & 0.22 & 1.55 & .123 \\
\hline MTurk & (Constant) & 5.74 & 0.11 & 51.52 & $<.001$ \\
\hline \multirow[t]{8}{*}{$d f=413$} & Anxious Attachment Score (Centered) & -0.10 & 0.09 & -1.08 & .279 \\
\hline & Avoidant Attachment Score (Centered) & -0.37 & 0.11 & -3.35 & .001 \\
\hline & Negative Scenario Condition & -0.15 & 0.16 & -0.97 & .332 \\
\hline & Positive Scenario Condition & 0.16 & 0.16 & 1.04 & .299 \\
\hline & $\begin{array}{l}\text { Anxious Attachment by Negative Scenario } \\
\text { Interaction }\end{array}$ & 0.23 & 0.13 & 1.83 & .068 \\
\hline & $\begin{array}{l}\text { Anxious Attachment by Positive Scenario } \\
\text { Interaction }\end{array}$ & 0.02 & 0.13 & 0.13 & .896 \\
\hline & $\begin{array}{l}\text { Avoidant Attachment by Negative Scenario } \\
\text { Interaction }\end{array}$ & -0.15 & 0.15 & -0.98 & .326 \\
\hline & $\begin{array}{l}\text { Avoidant Attachment by Positive Scenario } \\
\text { Interaction }\end{array}$ & -0.06 & 0.17 & -0.35 & .724 \\
\hline
\end{tabular}


Table 15

Moderated Regression Analyses of Goal Motivation Separated by Sample

\begin{tabular}{|c|c|c|c|c|c|}
\hline Sample & Variables & $B$ & $S E$ & $t$ & $P$ \\
\hline Student & (Constant) & 6.28 & 0.11 & 57.65 & $<.001$ \\
\hline \multirow[t]{8}{*}{$d f=220$} & Anxious Attachment Score (Centered) & -0.25 & 0.11 & -2.37 & .018 \\
\hline & Avoidant Attachment Score (Centered) & -0.14 & 0.12 & -1.13 & .260 \\
\hline & Negative Scenario Condition & -0.32 & 0.16 & -2.04 & .042 \\
\hline & Positive Scenario Condition & 0.02 & 0.15 & 0.18 & .854 \\
\hline & $\begin{array}{l}\text { Anxious Attachment by Negative Scenario } \\
\text { Interaction }\end{array}$ & 0.30 & 0.15 & 1.97 & .050 \\
\hline & $\begin{array}{l}\text { Anxious Attachment by Positive Scenario } \\
\text { Interaction }\end{array}$ & 0.13 & 0.15 & 0.82 & .414 \\
\hline & $\begin{array}{l}\text { Avoidant Attachment by Negative Scenario } \\
\text { Interaction }\end{array}$ & -0.19 & 0.17 & -1.08 & .284 \\
\hline & $\begin{array}{l}\text { Avoidant Attachment by Positive Scenario } \\
\text { Interaction }\end{array}$ & 0.03 & 0.19 & 0.56 & .875 \\
\hline MTurk & (Constant) & 6.25 & 0.09 & 73.91 & $<.001$ \\
\hline \multirow[t]{8}{*}{$d f=413$} & Anxious Attachment Score (Centered) & -0.15 & 0.07 & -2.24 & .025 \\
\hline & Avoidant Attachment Score (Centered) & -0.14 & 0.08 & -1.64 & .102 \\
\hline & Negative Scenario Condition & -0.04 & 0.12 & -0.31 & .754 \\
\hline & Positive Scenario Condition & 0.16 & 0.12 & 1.37 & .172 \\
\hline & $\begin{array}{l}\text { Anxious Attachment by Negative Scenario } \\
\text { Interaction }\end{array}$ & 0.15 & 0.10 & 1.61 & .109 \\
\hline & $\begin{array}{l}\text { Anxious Attachment by Positive Scenario } \\
\text { Interaction }\end{array}$ & 0.07 & 0.10 & 0.73 & .463 \\
\hline & $\begin{array}{l}\text { Avoidant Attachment by Negative Scenario } \\
\text { Interaction }\end{array}$ & -0.00 & 0.12 & -0.02 & .984 \\
\hline & $\begin{array}{l}\text { Avoidant Attachment by Positive Scenario } \\
\text { Interaction }\end{array}$ & -0.18 & 0.13 & -1.40 & .163 \\
\hline
\end{tabular}




\section{Appendix H}

Table 16

Moderated Regression Analyses of Goal Control Controlling for Goal Importance and Commitment

\begin{tabular}{lllll}
\hline Variables & $B$ & $S E$ & $t$ & $p$ \\
\hline (Constant) & 4.02 & 0.46 & 8.75 & $<.001$ \\
Anxious Attachment Score (Centered) & -0.03 & 0.07 & -0.40 & .686 \\
Avoidant Attachment Score (Centered) & -0.00 & 0.09 & -0.03 & .980 \\
Negative Scenario Condition & -0.12 & 0.12 & -1.05 & .295 \\
Positive Scenario Condition & 0.22 & 0.12 & 1.93 & .054 \\
Data Source & -0.28 & 0.10 & -2.62 & .009 \\
Goal Importance & 0.20 & 0.08 & 2.72 & .007 \\
Goal Commitment & 0.12 & 0.06 & 2.04 & .041 \\
Anxious Attachment by Negative Scenario Interaction & 0.00 & 0.10 & 0.04 & .966 \\
Anxious Attachment by Positive Scenario Interaction & -0.70 & 0.10 & -1.64 & .101 \\
Avoidant Attachment by Negative Scenario & -0.07 & 0.12 & -0.60 & .549 \\
Interaction & & & & \\
Avoidant Attachment by Positive Scenario Interaction & 0.13 & 0.13 & 0.19 & .850 \\
\hline
\end{tabular}

Table 17

Moderated Regression Analyses of Goal Focus Controlling for Goal Importance and Commitment

\begin{tabular}{lllll}
\hline Variables & $B$ & $S E$ & $t$ & $p$ \\
\hline (Constant) & 2.33 & 0.41 & 5.71 & $<.001$ \\
Anxious Attachment Score (Centered) & -0.15 & 0.07 & -2.27 & .024 \\
Avoidant Attachment Score (Centered) & -0.07 & 0.08 & -0.91 & .362 \\
Negative Scenario Condition & -0.16 & 0.12 & -1.49 & .138 \\
Positive Scenario Condition & 0.11 & 0.12 & 0.99 & .321 \\
Goal Importance & 0.11 & 0.07 & 1.66 & .098 \\
Goal Commitment & 0.41 & 0.05 & 7.64 & $<.001$ \\
Anxious Attachment by Negative Scenario Interaction & 0.15 & 0.09 & 1.68 & .093 \\
Anxious Attachment by Positive Scenario Interaction & 0.03 & 0.10 & 0.32 & .751 \\
Avoidant Attachment by Negative Scenario & -0.17 & 0.11 & -1.51 & .132 \\
Interaction & & & & \\
Avoidant Attachment by Positive Scenario Interaction & -0.07 & 0.12 & -0.55 & .585 \\
\hline
\end{tabular}


Table 18

Moderated Regression Analyses of Goal Distraction Controlling for Goal Importance and Commitment

\begin{tabular}{lllll}
\hline Variables & $B$ & $S E$ & $t$ & $p$ \\
\hline (Constant) & 6.04 & 0.64 & 9.50 & $<.001$ \\
Anxious Attachment Score (Centered) & 0.31 & 0.10 & 3.13 & .002 \\
Avoidant Attachment Score (Centered) & 0.11 & 0.12 & 0.94 & .347 \\
Negative Scenario Condition & 0.09 & 0.16 & 0.52 & .604 \\
Positive Scenario Condition & -0.08 & 0.16 & -0.53 & .599 \\
Data Source & -0.45 & 0.14 & -3.23 & .001 \\
Goal Importance & 0.07 & 0.10 & 0.72 & .474 \\
Goal Commitment & -0.21 & 0.08 & -2.60 & .009 \\
Anxious Attachment by Negative Scenario Interaction & -0.14 & 0.14 & -1.01 & .311 \\
Anxious Attachment by Positive Scenario Interaction & 0.06 & 0.14 & 0.41 & .686 \\
Avoidant Attachment by Negative Scenario Interaction & -0.05 & 0.16 & -0.33 & .740 \\
Avoidant Attachment by Positive Scenario Interaction & -0.20 & 0.19 & -1.07 & .284 \\
\hline
\end{tabular}

Table 19

Moderated Regression Analyses of Partner Support Controlling for Goal Importance and Commitment

\begin{tabular}{lllll}
\hline Variables & $B$ & $S E$ & \multicolumn{1}{c}{$t$} & $p$ \\
\hline (Constant) & 5.38 & 0.47 & 11.50 & $<.001$ \\
Anxious Attachment Score (Centered) & -0.07 & 0.07 & -0.95 & .342 \\
Avoidant Attachment Score (Centered) & -0.36 & 0.09 & -4.09 & $<.001$ \\
Negative Scenario Condition & -0.22 & 0.12 & -1.82 & .069 \\
Positive Scenario Condition & 0.14 & 0.12 & 1.17 & .242 \\
Data Source & -0.17 & 0.10 & -1.63 & .104 \\
Goal Importance & -0.04 & 0.08 & -0.48 & .633 \\
Goal Commitment & 0.15 & 0.06 & 2.50 & .013 \\
Anxious Attachment by Negative Scenario Interaction & 0.18 & 0.10 & 1.73 & .083 \\
Anxious Attachment by Positive Scenario Interaction & -0.05 & 0.11 & -0.47 & .637 \\
Avoidant Attachment by Negative Scenario Interaction & -0.20 & 0.12 & -1.67 & .096 \\
Avoidant Attachment by Positive Scenario Interaction & 0.06 & 0.14 & 0.42 & .677 \\
\hline
\end{tabular}


Table 20

Moderated Regression Analyses of Partner Support Controlling for Goal Importance and Commitment

\begin{tabular}{llccc}
\hline Variables & $B$ & $S E$ & $t$ & $p$ \\
\hline (Constant) & 2.51 & 0.31 & 8.04 & $<.001$ \\
Anxious Attachment Score (Centered) & -0.11 & 0.05 & -2.09 & .037 \\
Avoidant Attachment Score (Centered) & -0.08 & 0.06 & -1.28 & .201 \\
Negative Scenario Condition & -0.15 & 0.08 & -1.81 & .071 \\
Positive Scenario Condition & 0.11 & 0.08 & 1.35 & .177 \\
Goal Importance & 0.22 & 0.05 & 4.20 & $<.001$ \\
Goal Commitment & 0.37 & 0.04 & 8.99 & $<.001$ \\
Anxious Attachment by Negative Scenario Interaction & 0.10 & 0.07 & 1.47 & .142 \\
Anxious Attachment by Positive Scenario Interaction & 0.05 & 0.07 & 0.66 & .508 \\
Avoidant Attachment by Negative Scenario Interaction & -0.06 & 0.08 & -0.74 & .462 \\
Avoidant Attachment by Positive Scenario Interaction & -0.04 & 0.09 & -0.47 & .639 \\
\hline
\end{tabular}




\section{Appendix I}

Table 21

High Importance Moderated Regression Analyses of Relationship Satisfaction

\begin{tabular}{llllll}
\hline Goal Importance & Variables & $b$ & $S E$ & $t$ & $p$ \\
\hline High & (Constant) & 6.13 & 0.10 & 62.42 & $<.001$ \\
& Anxious Attachment Score (Centered) & -0.12 & 0.08 & -1.47 & .141 \\
& Avoidant Attachment Score (Centered) & -0.40 & 0.10 & -4.06 & $<.001$ \\
& Negative Scenario Condition & -0.72 & 0.14 & -5.16 & $<.001$ \\
& Positive Scenario Condition & -0.01 & 0.14 & -0.07 & .947 \\
& Anxious Attachment by Negative Scenario & 0.20 & 0.12 & 1.68 & .094 \\
& Interaction & & & & \\
& Anxious Attachment by Positive Scenario & 0.00 & 0.12 & 0.00 & 1.000 \\
& Interaction & & & & \\
& Avoidant Attachment by Negative & -0.15 & 0.14 & -1.05 & .297 \\
& Scenario Interaction & & & & \\
& Avoidant Attachment by Positive Scenario & -0.02 & 0.16 & -0.16 & .877 \\
& Interaction & & & & \\
\hline
\end{tabular}

Table 22

High Importance Moderated Regression Analyses of Goal Control

\begin{tabular}{llllll}
\hline Goal Importance & Variables & $b$ & $S E$ & $t$ & $p$ \\
\hline High & (Constant) & 6.15 & 0.20 & 31.02 & $<.001$ \\
$d f=559$ & Anxious Attachment Score (Centered) & -0.06 & 0.08 & -0.75 & .455 \\
& Avoidant Attachment Score (Centered) & -0.01 & 0.09 & -0.12 & .905 \\
& Negative Scenario Condition & -0.05 & 0.13 & -0.39 & .659 \\
& Positive Scenario Condition & 0.25 & 0.13 & 1.98 & .048 \\
& Sample Source & -0.27 & 0.10 & -2.48 & .014 \\
& Anxious Attachment by Negative Scenario & 0.07 & 0.11 & 0.61 & .539 \\
& Interaction & & & & \\
& Anxious Attachment by Positive Scenario & -0.15 & 0.11 & -1.36 & .176 \\
& Interaction & & & & \\
& Avoidant Attachment by Negative & -0.04 & 0.13 & -0.29 & .769 \\
& Scenario Interaction & & & & \\
& Avoidant Attachment by Positive Scenario & -0.02 & 0.14 & -0.11 & .917 \\
& Interaction & & & & \\
\hline
\end{tabular}


Table 23

High Importance Moderated Regression Analyses of Goal Focus

\begin{tabular}{llllll}
\hline Goal Importance & Variables & $b$ & $S E$ & $t$ & $p$ \\
\hline High & (Constant) & 5.72 & 0.09 & 67.55 & $<.001$ \\
$d f=560$ & Anxious Attachment Score (Centered) & -0.25 & 0.07 & -3.41 & .001 \\
& Avoidant Attachment Score (Centered) & -0.13 & 0.09 & -1.58 & .116 \\
& Negative Scenario Condition & -0127 & 0.12 & -1.03 & .304 \\
& Positive Scenario Condition & 0.13 & 0.12 & 1.11 & .267 \\
& Anxious Attachment by Negative Scenario & 0.23 & 0.10 & 2.26 & .024 \\
& Interaction & & & & \\
& Anxious Attachment by Positive Scenario & 0.10 & 0.10 & 0.97 & .331 \\
& Interaction & & & & \\
& Avoidant Attachment by Negative & -0.11 & 0.12 & -0.91 & .364 \\
& Scenario Interaction & & & & \\
& Avoidant Attachment by Positive Scenario & -0.11 & 0.14 & -0.81 & .416 \\
& Interaction & & & & \\
\hline
\end{tabular}

Table 24

High Importance Moderated Regression Analyses of Goal Distraction

\begin{tabular}{llllll}
\hline Goal Importance & Variables & $b$ & $S E$ & $t$ & $p$ \\
\hline High & (Constant) & 5.39 & 0.28 & 19.37 & $<.001$ \\
$d f=559$ & Anxious Attachment Score (Centered) & 0.38 & 0.11 & 3.63 & $<.001$ \\
& Avoidant Attachment Score (Centered) & 0.18 & 0.13 & 1.45 & .148 \\
& Negative Scenario Condition & 0.12 & 0.18 & 0.68 & .497 \\
& Positive Scenario Condition & -0.07 & 0.18 & -0.39 & .696 \\
& Sample Source & -0.59 & 0.15 & -3.89 & $<.001$ \\
& Anxious Attachment by Negative Scenario & -0.23 & 0.15 & -1.52 & .129 \\
& Interaction & & & & \\
& Anxious Attachment by Positive Scenario & -0.00 & 0.15 & -0.02 & .988 \\
& Interaction & & & & \\
& Avoidant Attachment by Negative & -0.17 & 0.18 & -0.95 & .340 \\
& Scenario Interaction & & & & \\
& Avoidant Attachment by Positive Scenario & -0.26 & 0.20 & -1.27 & .205 \\
& Interaction & & & & \\
\hline
\end{tabular}


Table 25

High Importance Moderated Regression Analyses of Partner Support

\begin{tabular}{llllll}
\hline Goal Importance & Variables & $b$ & $S E$ & $t$ & $p$ \\
\hline High & (Constant) & 6.00 & 0.20 & 29.48 & $<.001$ \\
& Anxious Attachment Score (Centered) & -0.09 & 0.08 & -1.09 & .276 \\
& Avoidant Attachment Score (Centered) & -0.35 & 0.09 & -3.85 & $<.001$ \\
& Negative Scenario Condition & -0.22 & 0.13 & -1.72 & .086 \\
& Positive Scenario Condition & 0.10 & 0.13 & 0.77 & .441 \\
& Data Source & -0.09 & 0.11 & -0.80 & .425 \\
& Anxious Attachment by Negative Scenario & 0.18 & 0.11 & 1.70 & .090 \\
& Interaction & & & & \\
& Anxious Attachment by Positive Scenario & -0.05 & 0.11 & -0.43 & .671 \\
& Interaction & & & & \\
& Avoidant Attachment by Negative & -0.18 & 0.13 & -1.42 & .156 \\
& Scenario Interaction & & & & \\
& Avoidant Attachment by Positive Scenario & 0.02 & 0.15 & 0.10 & .919 \\
& Interaction & & & & \\
\hline
\end{tabular}

Table 26

High Importance Moderated Regression Analyses of Goal Motivation

\begin{tabular}{llllll}
\hline Goal Importance & Variables & $b$ & $S E$ & $t$ & $p$ \\
\hline High & (Constant) & 6.37 & 0.07 & 95.81 & $<.001$ \\
& Anxious Attachment Score (Centered) & -0.19 & 0.06 & -3.42 & .001 \\
& Avoidant Attachment Score (Centered) & -0.13 & 0.07 & -2.01 & .105 \\
& Negative Scenario Condition & -0.10 & 0.10 & -1.09 & .275 \\
& Positive Scenario Condition & 0.08 & 0.09 & 0.83 & .406 \\
& Anxious Attachment by Negative Scenario & 0.17 & 0.08 & 2.16 & .031 \\
& Interaction & & & & \\
& Anxious Attachment by Positive Scenario & 0.12 & 0.08 & 1.45 & .147 \\
& Interaction & & & & \\
& Avoidant Attachment by Negative & 0.06 & 0.09 & 0.61 & .545 \\
& Scenario Interaction & & & & \\
& Avoidant Attachment by Positive Scenario & -0.08 & 0.11 & -0.74 & .459 \\
& Interaction & & & & \\
\hline
\end{tabular}




\section{Appendix J}

Table 27

Moderated Regression Analyses of Relationship Satisfaction (No Control Group)

\begin{tabular}{lllll}
\hline Variables & $B$ & $S E$ & $t$ & $p$ \\
\hline (Constant) & 5.76 & 0.07 & 80.29 & $<.001$ \\
Anxious Attachment Score (Centered) & -0.03 & 0.06 & -0.52 & .603 \\
Avoidant Attachment Score (Centered) & -0.53 & 0.08 & -6.63 & $<.001$ \\
Manipulation & 0.35 & 0.07 & 4.82 & $<.001$ \\
Anxious Attachment by Manipulation Interaction & 0.06 & 0.08 & 0.73 & .465 \\
Avoidant Attachment by Manipulation Interaction & -0.10 & 0.63 & -1.62 & .106 \\
\hline
\end{tabular}

Table 28

Moderated Regression Analyses of Goal Control (No Control Group)

\begin{tabular}{lllll}
\hline Variables & $B$ & $S E$ & $t$ & $p$ \\
\hline (Constant) & 5.91 & 0.22 & 27.06 & $<.001$ \\
Anxious Attachment Score (Centered) & -0.11 & 0.05 & -2.01 & .045 \\
Avoidant Attachment Score (Centered) & -0.08 & 0.07 & -1.22 & .224 \\
Manipulation & -0.12 & 0.13 & -0.95 & .345 \\
Data Source & 0.17 & 0.06 & 2.74 & .006 \\
Anxious Attachment by Manipulation Interaction & -0.10 & 0.05 & -1.82 & .070 \\
Avoidant Attachment by Manipulation Interaction & 0.02 & 0.07 & 0.26 & .793 \\
\hline
\end{tabular}

Table 29

Moderated Regression Analyses of Goal Focus (No Control Group)

\begin{tabular}{lllll}
\hline Variables & $B$ & $S E$ & $t$ & $p$ \\
\hline (Constant) & 5.63 & 0.06 & 94.12 & $<.001$ \\
Anxious Attachment Score (Centered) & -0.08 & 0.05 & -1.60 & .111 \\
Avoidant Attachment Score (Centered) & -0.25 & 0.07 & -3.80 & $<.001$ \\
Manipulation & 0.12 & 0.06 & 1.98 & .049 \\
Anxious Attachment by Manipulation Interaction & 0.02 & 0.07 & 0.23 & .821 \\
Avoidant Attachment by Manipulation Interaction & -0.08 & 0.05 & -1.58 & .116 \\
\hline
\end{tabular}


Table 30

Moderated Regression Analyses of Goal Distraction (No Control Group)

\begin{tabular}{lllll}
\hline Variables & $B$ & $S E$ & $t$ & $p$ \\
\hline (Constant) & 5.42 & 0.30 & 18.15 & $<.001$ \\
Anxious Attachment Score (Centered) & 0.28 & 0.07 & 3.88 & $<.001$ \\
Avoidant Attachment Score (Centered) & 0.00 & 0.09 & 0.05 & .964 \\
Manipulation & -0.60 & 0.17 & -3.42 & .001 \\
Data Source & -0.08 & 0.08 & -0.97 & .334 \\
Anxious Attachment by Manipulation Interaction & 0.11 & 0.07 & 1.50 & .136 \\
Avoidant Attachment by Manipulation Interaction & -0.07 & 0.09 & -0.73 & .462 \\
\hline
\end{tabular}

Table 31

Moderated Regression Analyses of Partner Support (No Control Group)

\begin{tabular}{lllll}
\hline Variables & $B$ & $S E$ & $t$ & $p$ \\
\hline (Constant) & 5.91 & 0.22 & 26.64 & $<.001$ \\
Anxious Attachment Score (Centered) & -0.02 & 0.05 & -0.31 & .757 \\
Avoidant Attachment Score (Centered) & -0.44 & 0.07 & -6.36 & $<.001$ \\
Manipulation & -0.08 & 0.13 & -0.64 & .521 \\
Data Source & 0.18 & 0.06 & 2.83 & .005 \\
Anxious Attachment by Manipulation Interaction & -0.12 & 0.05 & -2.21 & .027 \\
Avoidant Attachment by Manipulation Interaction & 0.13 & 0.07 & 1.80 & .072 \\
\hline
\end{tabular}

Table 32

Moderated Regression Analyses of Goal Motivation (No Control Group)

\begin{tabular}{lllll}
\hline Variables & $B$ & $S E$ & $t$ & $p$ \\
\hline (Constant) & 6.25 & 0.05 & 128.10 & $<.001$ \\
Anxious Attachment Score (Centered) & -0.05 & 0.04 & -1.13 & .259 \\
Avoidant Attachment Score (Centered) & -0.21 & 0.06 & -3.86 & $<.001$ \\
Manipulation & 0.11 & 0.05 & 2.34 & .020 \\
Anxious Attachment by Manipulation Interaction & -0.04 & 0.06 & -0.64 & .522 \\
Avoidant Attachment by Manipulation Interaction & -0.05 & 0.04 & -1.11 & .266 \\
\hline
\end{tabular}

